\title{
Nanometric palladium confined in mesoporous silica as efficient catalysts for toluene oxidation at low temperature
}

\author{
Chi Hea ${ }^{a}$, Fuwang Zhang ${ }^{\mathrm{a}}$, Lin Yue ${ }^{\mathrm{b}}$, Xuesong Shang ${ }^{\mathrm{a}}$, Jinsheng Chen ${ }^{\mathrm{a}, *}$, Zhengping Hao ${ }^{\mathrm{b}, * *}$ \\ a Key Lab of Urban Environment and Health, Institute of Urban Environment, Chinese Academy of Sciences, Xiamen 361021, PR China \\ ${ }^{\mathrm{b}}$ Department of Environmental Nano-materials, Research Center for Eco-Environmental Sciences, Chinese Academy of Sciences, Beijing 100085, PR China
}

\section{A R T I C L E I N F O}

\section{Article history:}

Received 10 June 2011

Received in revised form 4 September 2011

Accepted 19 September 2011

Available online 22 September 2011

\section{Keywords:}

Mesoporous silica

Two-solvents technique

Pd-confined

Controllable acidity

Volatile organic compounds

\begin{abstract}
A B S T R A C T
Short column SBA-15 supported Pd mesoporous catalysts with controllable acidity and expanded microporosity were firstly prepared through a simple "two-solvents" approach. The catalytic performances of the synthesized catalysts were evaluated for toluene oxidation. The characterization results reveal that $\mathrm{Al}$ atoms prefer to be tetrahedrally coordinated in the framework of the synthesized materials, and the acid sites can significantly promote Pd particle dispersion and metallic Pd oxidation due to their electrophilic characters. The Pd-confined catalysts possess high toluene turnover frequencies and toluene can be totally converted to $\mathrm{CO}_{2}$ and $\mathrm{H}_{2} \mathrm{O}$ below $210^{\circ} \mathrm{C}$. The oxidation reaction can be suppressed by water vapor due to the formation of inactive Pd-hydroxides, and the synthesized catalyst has a good hydrothermal stability and high tolerance to moisture. Both the specific surface area and the toluene adsorption/desorption property are not the main factors determining the catalytic activity. Overall, the toluene oxidation performance is closely related to the support microporosity and acidity, the Pd dispersion and the $\mathrm{CO}_{2}$ desorption capability.
\end{abstract}

(c) 2011 Elsevier B.V. All rights reserved.

\section{Introduction}

Volatile organic compounds (VOCs) emitted from transport and industrial processes are recognized as major contributors to air pollution and are dangerous to human health. Among them, BTX (i.e., benzene, toluene and xylene) are of particular concern due to their high toxicity for human beings [1-3]. Therefore, the development of effective and reliable methods for complete elimination of VOCs is of great importance considering their harmful effects on human health and the environment. In general, VOC catalytic oxidation technology with lots of distinguished advantages, such as high destructive efficiency and flexibility, low operation and energy cost, and low thermal $\mathrm{NO}_{x}$ emission, has been identified as one of the most efficient ways [4-6]. In order to make the reaction economically competitive, it is of great importance to explore higher active catalysts to perform at low temperatures. Currently, different types of catalysts, such as supported noble metals, transition metal oxides and their mixtures, are being widely investigated in VOC oxidation [7]. Particularly, supported Pd catalysts are extensively studied considering their superior activity, excellent thermal stability and high tolerance to moisture [8].

\footnotetext{
* Corresponding author. Tel.: +86 10 62923564; fax: +86 1062923564 .

** Corresponding author. Tel.: +86 592 6190765; fax: +86 5926190765 .

E-mail addresses: jschen@iue.ac.cn (J. Chen), zpinghao@rcees.ac.cn (Z. Hao).
}

It is generally accepted that the support nature plays an important role in the improvement of catalytic oxidation efficiency [9]. Up to now, various types of supports such as zirconia, alumina, silica and porous materials have been extensively explored in VOC catalytic oxidation. Among them, SBA-15 type support possesses high surface area, large and tunable pore size, thick pore wall and micropores in the primary mesoporous pore channels [10], appears to be one of the best supports for Pd-loaded catalysts. However, due to the long and curved mesostructures and densely packed secondary morphologies of traditional SBA-15 [11], the diffusion of large molecules within their pore channels may be suppressed. As is known, mesoporous SBA-15 with different morphologies, such as fiber, rope, doughnut, sphere, gyroid and discoid, has been synthesized via different approaches [12]. Recently, a facile synthesis route for preparing SBA-15 type material with novel platelet mesostructure (pore length $<350 \mathrm{~nm}$ ) by introducing a small amount of $\mathrm{Zr}(\mathrm{IV})$ ions in the synthesis solution was reported by Cheng et al. [13]. These materials may be superior to the conventional SBA-15 in facilitating molecular diffusion and less possibility of pore blockage, especially in the reactions of bulky molecules. However, the performance and potential application of these novel mesoporous silica in VOC deep elimination was seldom reported [14].

In our previous work, we found that the catalytic activity of Pdsupported catalysts was much dependent on the microporosity and acid character of supports $[15,16]$. The micropores in the supports can enhance the diffusion rate for transport in catalytic processes, 
and the acid sites can promote the active phase dispersion and the oxidation process of catalysts, and these results were also proposed by other researchers [9]. As is known, SBA-15 type support is purely siliceous material, and the micropore in typical SBA-15 is rather limited, hence limiting its practical application. Kruk et al. [17] reported that the micropore volume in SBA-15 is dependent to some extent on the synthesis/ageing temperature. Similarly, we found that the microporosity of mesoporous SBA- 15 could be systematically controlled by varying the $\mathrm{SiO}_{2} / \mathrm{P} 123$ molar ratio and ageing temperature [15]. However, it is very difficult to prepare Al-containing mesoporous SBA-15 type materials as Al species will exist only in the cationic form rather than the corresponding oxo species under strongly acidic conditions. "Direct-synthesis" [18] and "post-grafting" [19] are two representative methods for the introduction of heteroatoms. The procedure of direct-synthesis is relatively simple, however, only a small amount of heteroatoms can be introduced into the mesoporous silica. Compared with directsynthesis, post-grafting can introduce more heteroatoms into the framework of mesoporous silica, however, the post-grafting routes are very complicated and the uniform mesostructure of products are sometimes severely destroyed [20]. Recently, Wu et al. [21] reported a simple and efficient "pH-adjusting" approach which can introduce large amount of heteroatoms into mesoporous silica without destroying its original mesostructure.

On the other hand, recent work suggested that noble metal confined catalysts possess high catalytic activity and stability as the pore channels of supports have the potential ability to inhibit active particles growth and aggregation during reactions [22]. Various strategies were developed for incorporating metal nanoparticles into mesoporous silica, such as chemical vapor deposition [23], wet impregnation [7,16,24,25] and ion exchange [26]. However, the aforementioned approaches could not ensure the encapsulation of Pd nanoparticles inside the mesoporous channels, and hence large metal aggregates would form on the external surface of supports during thermal treatments or reactions. Noteworthily, researchers suggested that post grafting approach can control the location and size of metal nanoparticles. For instance, highly dispersed Ag and Pd encapsulated catalysts were successfully synthesized by selectively functionalizing the outer and inner surfaces of SBA-15 $[27,28]$. However, the grafting method is relatively complicated and requires many expensive coupling agents (trimethylchlorosilane, 3-aminopropyltrimethoxysilane, etc.). Recently, researchers developed a simple and economical "two-solvents" technique, which allows the preparation of highly dispersed metal nanoparticles within silica mesopores [29]. Unfortunately, the synthesis of highly dispersed Pd nanoparticle confined mesoporous catalysts through this novel method has not been reported.

In this work, the short column SBA-15 type supports with expanded microporosity and enhanced acidity were firstly reported. Moreover, the synthesized materials that supported Pd catalysts were prepared via conventional impregnation method and novel "two-solvents" approach. The aim of this research is to comprehensively investigate the catalytic properties of these novel Pd-confined catalysts in VOC oxidation reaction, and emphatically illuminate the relationship between the material textural properties, the active phase state, the adsorption/desorption capability of reactant/product and catalytic activity. We could anticipate that these novel nanometric Pd-confined catalysts probably have potential applications in catalysis, separation and adsorption processes.

\section{Experimental}

\subsection{Support preparation}

The short column SBA-15 type supports used in this work were prepared by dissolving $4 \mathrm{~g}$ of Pluronic P123 $\left(\mathrm{EO}_{20} \mathrm{PO}_{70} \mathrm{EO}_{20}\right)$ in $160 \mathrm{~g}$ of $2 \mathrm{M} \mathrm{HCl}$ solution at $35^{\circ} \mathrm{C}$, followed by adding $9.1 \mathrm{ml}$ of tetraethyl orthosilicate (TEOS), $0.66 \mathrm{~g}$ of $\mathrm{ZrOCl}_{2}$ and different amounts of $\mathrm{Al}_{2}\left(\mathrm{SO}_{4}\right)_{3}$. The mixture was stirred at $35^{\circ} \mathrm{C}$ for $20 \mathrm{~h}$, and then aged at $85^{\circ} \mathrm{C}$ for $48 \mathrm{~h}$. After the procedures described above, the $\mathrm{pH}$ of the mixture was adjusted to 7.5 by adding $\mathrm{NH}_{4} \mathrm{OH}$ dropwise at room temperature and the obtained mixture was hydrothermally heated again at $85^{\circ} \mathrm{C}$ for $48 \mathrm{~h}$. The recovered soil was extensively washed with deionized water and dried at $60^{\circ} \mathrm{C}$ for $24 \mathrm{~h}$. Template removal was performed by calcinations in air using two successive procedures, i.e., heating at $350^{\circ} \mathrm{C}$ for $3 \mathrm{~h}$ and then at $550^{\circ} \mathrm{C}$ for $4 \mathrm{~h}$, to prevent the silica matrix from shrinking, and hence maintained the original size and volume of micro- and mesopores. Afterwards, the calcined sample was subjected to exchange with a $0.1 \mathrm{M} \mathrm{NH}_{4} \mathrm{NO}_{3}$ solution for $24 \mathrm{~h}$ at room temperature and followed by calcination at $500{ }^{\circ} \mathrm{C}$ for $4 \mathrm{~h}$ to obtain the protonated form. In this research, five samples with different Si/Al molar ratios $(x)$, denoted as SC $-x(x=10$, $20,40,80$ and 160$)$, were prepared. For comparison, conventional SBA-15 was also synthesized following the literature procedure [30].

\subsection{Catalysts synthesis}

The Pd-confined catalysts with a theoretical Pd loading of $0.5 \mathrm{wt}$ \% were prepared according to the "two-solvents" technique. Firstly, SBA-15 and SC- $x$ samples were suspended in dry hexane, used as the hydrophobic solvent. Then, a desired amount of $\mathrm{PdCl}_{2}$ solution (quantity corresponding to the pore volume determined by $\mathrm{N}_{2}$ sorption) was added dropwise, and the mixture solution was vigorously stirred for $2 \mathrm{~h}$ at room temperature. Afterwards, the solid was recovered by filtration and dried at $50^{\circ} \mathrm{C}$ in air, followed by calcination at $500^{\circ} \mathrm{C}$ for $4 \mathrm{~h}$ (heating rate $2{ }^{\circ} \mathrm{C} / \mathrm{min}$ ) and reduction in a pure $\mathrm{H}_{2}$ stream $(30 \mathrm{ml} / \mathrm{min})$ at $480^{\circ} \mathrm{C}$ for $2 \mathrm{~h}$. The synthesized catalysts were denoted as $\mathrm{Pd} / \mathrm{SBA}-15-\mathrm{T}$ and $\mathrm{Pd} / \mathrm{SC}-x$, respectively.

For comparison, the Pd-supported catalyst was also prepared by impregnation method. Firstly, the mesoporous SBA-15 was evenly impregnated with a $\mathrm{PdCl}_{2}$ aqueous solution at room temperature. Then, the obtained sample was dried at $50^{\circ} \mathrm{C}$ for $24 \mathrm{~h}$, followed by calcination at $500^{\circ} \mathrm{C}$ for $4 \mathrm{~h}$. Finally, the calcined sample was further reduced in a pure $\mathrm{H}_{2}$ stream $\left(30 \mathrm{ml} / \mathrm{min}\right.$ ) at $480^{\circ} \mathrm{C}$ for $2 \mathrm{~h}$ to obtain the Pd/SBA-15 catalyst.

\subsection{Catalyst characterizations}

X-ray diffraction (XRD) patterns were recorded on a Rigaku TTR2 powder diffraction system using $\mathrm{Cu} K \alpha$ radiation $(\lambda=0.15418 \mathrm{~nm})$ in the $2 \theta$ range of $0.7-5^{\circ}$ (scanning rate of $0.5^{\circ} / \mathrm{min}$ ) and $10-80^{\circ}$ (scanning rate of $4^{\circ} / \mathrm{min}$ ), respectively. $\mathrm{N}_{2}$ adsorption/desorption isotherms of catalysts at $77 \mathrm{~K}$ were collected on a gas sorption analyzer NOVA1200. All samples were degassed under vacuum at $300^{\circ} \mathrm{C}$ for $3 \mathrm{~h}$ before the measurement. The total pore volume was estimated from the amount of nitrogen adsorbed at a relative pressure $\left(P / P_{0}\right)$ of $c a$. 0.99 . The specific surface area was calculated using the Brunauer-Emmett-Teller (BET) method (the micropore volume was estimated by the $t$-plot method) and the pore size distribution was derived from the desorption branch of the $\mathrm{N}_{2}$ isotherm using the Barrett-Joyner-Halenda (BJH) method. Field emission scanning electron microscopy (FE-SEM) images were recorded on a Hitachi S-4800 microscope equipped with EDX detector for composition analysis of the synthesized catalysts. Transmission electron microscopy (TEM) images were collected on a Hitachi H-7500 microscope operating at an acceleration voltage of $80 \mathrm{kV}$. The exact Pd content in all calcined samples was determined by inductively coupled plasma optical emission spectroscopy (ICPOES) on an OPTIMA 2000. The palladium dispersion was assessed by $\mathrm{H}_{2}$ chemisorption at $25^{\circ} \mathrm{C}$, i.e., the molar ratio of $\mathrm{H} / \mathrm{Pd}$. The mean Pd crystallite size $\left(D_{\mathrm{C}}\right)$ was further estimated from the equation: 

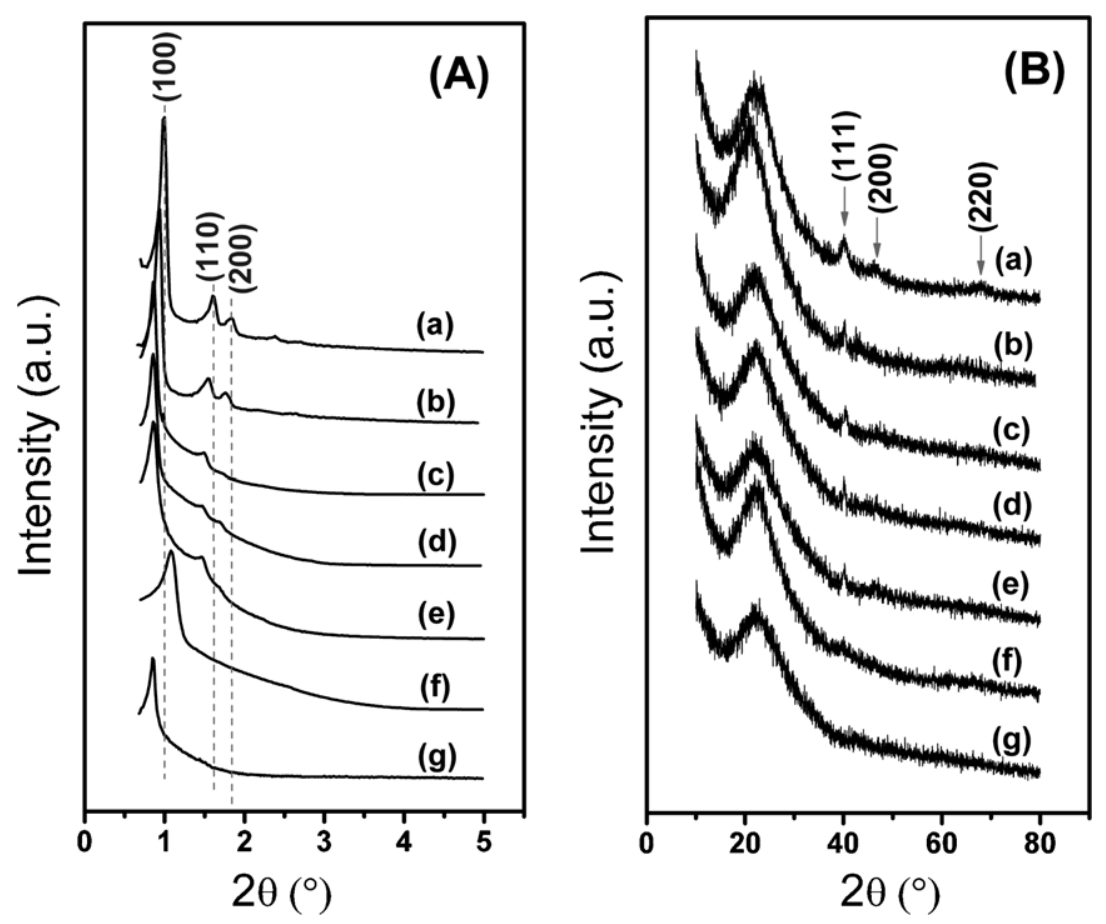

Fig. 1. SA-XRD and WA-XRD patterns of (a) Pd/SBA-15, (b) Pd/SBA-15-T, (c) Pd/SC-160, (d) Pd/SC-80, (e) Pd/SC-40, (f) Pd/SC-20 and (g) Pd/SC-10.

$D_{\mathrm{c}}(\mathrm{nm})=112 /($ percentage of Pd exposed) [31], assuming that the Pd crystallites were spherical with a surface atom density of $1.27 \times 10^{19}$ atoms $/ \mathrm{m}^{2}$. Temperature programmed reduction (TPR) experiments were performed on a Micromeritics chemisorb 2720. Prior to reduction, $0.2 \mathrm{~g}$ of the catalyst was dried in a helium flow $\left(50 \mathrm{ml} / \mathrm{min}\right.$ ) at $300^{\circ} \mathrm{C}$ for $1 \mathrm{~h}$. Then the sample was reduced under a $\mathrm{H}_{2} / \mathrm{He}(2 / 98 \%, \mathrm{v} / \mathrm{v})$ mixture from 25 to $300^{\circ} \mathrm{C}$ with a heating rate of $10^{\circ} \mathrm{C} /$ min. Temperature programmed desorption of $\mathrm{NH}_{3}, \mathrm{CO}_{2}$ and toluene $\left(\mathrm{NH}_{3}-\mathrm{TPD}, \mathrm{CO}_{2}\right.$-TPD and toluene-TPD) were preformed on a Micromeritics chemisorb 2720 equipped with a TCD. Typically, $0.1 \mathrm{~g}$ of the catalyst was pre-treated in a pure helium flow $\left(50 \mathrm{ml} / \mathrm{min}\right.$ ) at $300^{\circ} \mathrm{C}$ for $1 \mathrm{~h}$ and then cooled to room temperature $\left(25^{\circ} \mathrm{C}\right)$ prior to adsorption of $\mathrm{NH}_{3}\left(\mathrm{NH}_{3} / \mathrm{He}, 2 \% / 98 \%, \mathrm{v} / \mathrm{v}\right), \mathrm{CO}_{2}$ $\left(\mathrm{CO}_{2} / \mathrm{He}, 5 \% / 95 \%, \mathrm{v} / \mathrm{v}\right)$ and toluene $(1000 \mathrm{ppm})$ for $2 \mathrm{~h}$. After being saturated with $\mathrm{NH}_{3}, \mathrm{CO}_{2}$ and toluene, the catalyst was flushed with pure helium flow $(50 \mathrm{ml} / \mathrm{min})$ for $1 \mathrm{~h}$ at room temperature. The desorption profile of $\mathrm{NH}_{3}-\mathrm{TPD}, \mathrm{CO}_{2}$-TPD and toluene-TPD were recorded online at a heating rate of $10^{\circ} \mathrm{C} / \mathrm{min}$. X-ray photoelectron spectroscopy (XPS) experiments were carried out on a Quantum 2000 instrument under high vacuum $\left(<5 \times 10^{-10}\right.$ Torr $)$ using $\mathrm{Al} \mathrm{K \alpha}$ as the exciting radiation at a constant pass energy of $1486.6 \mathrm{eV}$. The $\mathrm{C} 1 \mathrm{~s}$ peak was used to calibrate the binding energy. Solid-state ${ }^{27} \mathrm{Al}$ MAS NMR spectra were performed on a Bruker AV-400 spectrometer equipped with a $4 \mathrm{~mm} \mathrm{CP} / \mathrm{MAS}$ detector, the spinning frequency was $13 \mathrm{kHz}$, and the chemical shifts were referred to $\mathrm{Al}\left(\mathrm{H}_{2} \mathrm{O}\right)_{6}{ }^{3+}$.

\subsection{Catalytic oxidation activities}

All evaluation experiments were performed in a continuousflow fixed-bed reactor at the atmospheric pressure, consisting of a stainless steel tube ( $6 \mathrm{~mm}$ i.d.) that was filled with the catalyst. The VOC-containing gas was generated by bubbling air through the VOC saturator, and then further diluted with another air stream before reaching the reaction bed. The temperatures of the catalyst bed and tubular electric furnace were monitored automatically by E-type thermocouples. In each test, $300 \mathrm{mg}$ of the catalyst (40-60 mesh) was placed at the middle of the tube reactor and the total flow rate was kept at $350 \mathrm{ml} / \mathrm{min}$, i.e., gas hourly space velocity (GHSV) of
$32,000 \mathrm{~h}^{-1}$, and the $\mathrm{O}_{2}$ feed concentration was kept at about $21 \%$ $(\mathrm{v} / \mathrm{v})$. In each test, the catalyst bed temperature was first raised to $130^{\circ} \mathrm{C}$ with the feed stream passing and stabilized for $30 \mathrm{~min}$. Then the temperature was increased to the next one at a heating rate of $5^{\circ} \mathrm{C} / \mathrm{min}$ and stabilized for $20 \mathrm{~min}$ prior to online analysis of the effluent gas composition in an Agilent gas chromatograph equipped with an FID and a TCD. VOC concentrations in the feed and effluent streams were determined with the FID after being separated in an AB-GASPRO capillary column, and $\mathrm{CO} / \mathrm{CO}_{2}$ in the effluent stream were separated in a TDX-01 column and their concentrations were determined with the TCD. If required, water vapor (2.0 vol.\%) was fed into the reactor through the evaporator at $100{ }^{\circ} \mathrm{C}$.

\section{Results}

\subsection{Structural and textural properties of the synthesized materials}

\subsection{1. $X R D$ and $N_{2}$ adsorption/desorption}

The small-angle XRD (SA-XRD) patterns of all synthesized materials in the $2 \theta$ range of $0.7-5^{\circ}$ are shown in Fig. 1(A). All samples exhibit one intensity peak at $0.8-1.0^{\circ}$ along with other two weak peaks at $1.3-2.0^{\circ}$, which can be assigned to the (100), (1 10$)$ and (2 00 ) reflections of the two-dimensional hexagonal mesostructure with a space group of $p 6 \mathrm{~mm}$ symmetry [32]. The well resolved diffraction peaks indicate that the incorporation of $\mathrm{Al}$ atoms has negligible effects on the original mesostructure of the synthesized catalysts. Besides, the (100), (1 1 10$)$ and (200) reflection becomes more intense and prominent with the decreasing of Al content, indicating that the hexagonal order is decreased to some extent with the introduction of $\mathrm{Al}$ species. Besides, it can be noticed that all diffraction peaks of Pd/SC- $x$ samples shift slightly to lower angles (i.e., $d_{100}$ and $a_{0}$ are slightly enlarged [22]) compared with the Pd/SBA-15 and Pd/SBA-15-T materials, suggesting that $\mathrm{Al}$ atoms are introduced into the frameworks of the $\mathrm{SC}-x$ host as the $\mathrm{Al}-\mathrm{O}$ bond length is longer than that of $\mathrm{Si}-\mathrm{O}$ bond. Fig. 1(B) shows the wide-angle XRD (WA-XRD) of the synthesized catalysts. The actual Pd loading of all prepared catalysts are close to $0.5 \mathrm{wt}$ \% (Fig. S1 
Table 1

Characteristic data of all synthesized catalysts.

\begin{tabular}{|c|c|c|c|c|c|c|c|c|}
\hline Sample & $\mathrm{Si} / \mathrm{Al} \mathrm{ratio}^{\mathrm{a}}$ & $\begin{array}{l}\mathrm{Pd}^{\mathrm{b}} \\
\text { (wt.\%) }\end{array}$ & $\mathrm{H} / \mathrm{Pd}^{\mathrm{c}}$ & $\begin{array}{l}D_{c} \\
(\mathrm{~nm})\end{array}$ & $\begin{array}{l}T_{10} \mathrm{~d} \\
\left({ }^{\circ} \mathrm{C}\right)\end{array}$ & $\begin{array}{l}T_{50}{ }^{d} \\
\left({ }^{\circ} \mathrm{C}\right)\end{array}$ & $\begin{array}{l}T_{90}{ }^{\mathrm{d}} \\
\left({ }^{\circ} \mathrm{C}\right)\end{array}$ & $\begin{array}{l}S_{90}{ }^{\mathrm{e}} \\
(\%)\end{array}$ \\
\hline Pd/SBA-15 & - & 0.49 & 0.31 & 3.6 & 168 & 207 & 227 & 97.8 \\
\hline Pd/SBA-15-T & - & 0.48 & 0.29 & 3.8 & 169 & 206 & 231 & 98.4 \\
\hline $\mathrm{Pd} / \mathrm{SC}-10$ & 8.74 & 0.49 & 0.64 & 1.7 & 159 & 183 & 198 & 99.5 \\
\hline $\mathrm{Pd} / \mathrm{SC}-20$ & 17.3 & 0.51 & 0.53 & 2.1 & 153 & 187 & 202 & 99.3 \\
\hline $\mathrm{Pd} / \mathrm{SC}-40$ & 29.6 & 0.47 & 0.42 & 2.6 & 162 & 199 & 214 & 98.9 \\
\hline $\mathrm{Pd} / \mathrm{SC}-80$ & 38.2 & 0.48 & 0.38 & 2.9 & 165 & 198 & 212 & 99.0 \\
\hline $\mathrm{Pd} / \mathrm{SC}-160$ & 79.1 & 0.5 & 0.34 & 3.3 & 176 & 205 & 218 & 98.8 \\
\hline
\end{tabular}

a Actual Si/Al ratio estimated by the EDS analysis.

b Actual Pd contents obtained by the ICP-OES analysis.

Molar ratio of adsorbed hydrogen atoms to the total palladium atoms.

d Temperatures at which $10 \%, 50 \%$ and $90 \%$ conversion of toluene.

e $\mathrm{CO}_{2}$ selectivity at which $90 \%$ conversion of toluene.

and Table 1 ). The broad diffraction peaks appeared at $2 \theta=23^{\circ}$ in all diffraction patterns can be ascribed to the amorphous silica [27]. In addition, three diffraction peaks at $2 \theta=40.1^{\circ}, 46.4^{\circ}$ and $67.9^{\circ}$ can be observed in the diffraction pattern of Pd/SBA-15, assigned to (111), (200) and (220) reflections of metallic Pd, respectively (JCPDS: 46-1043). The supports have significant influences on the Pd dispersion. For example, two broad diffraction peaks can be seen at $2 \theta=40.1^{\circ}, 46.4^{\circ}$ in the pattern of $\mathrm{Pd} / \mathrm{SC}-160$, while these peaks become weaker and broader for Pd/SC-20, and totally disappear for Pd/SC-10 (Fig. 1(B)).

Fig. 2 shows the $\mathrm{N}_{2}$ adsorption/desorption isotherms and pore size distribution of all synthesized catalysts. All samples possess the type IV isotherms (characteristic of mesoporous materials) and H1 type hysteresis loop according to the IUPAC classification [33], which indicated the two-dimensional $p 6 \mathrm{~mm}$ structure formed by open cylindrical mesopores [10], and this is in good agreement with the XRD results (Fig. 1). The adsorption isotherms of all Pd/SC- $x$ materials exhibit sharp increases at $P / P_{0}<0.1$ and $P / P_{0}=0.65-0.9$,

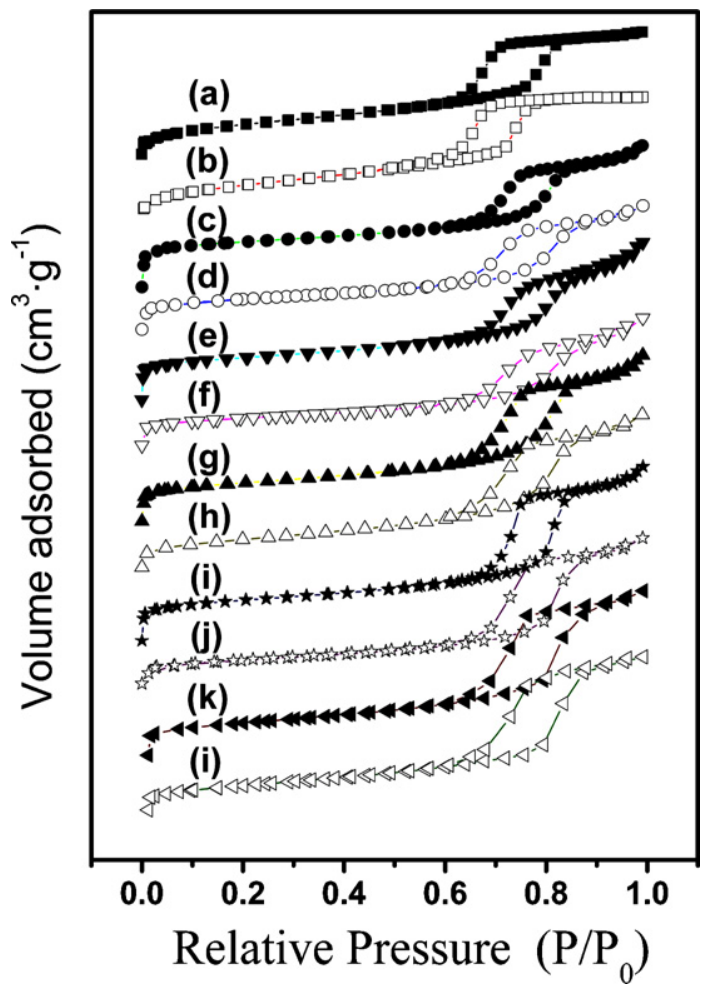

Fig. 2. $\mathrm{N}_{2}$ adsorption/desorption isotherms of various catalysts: (a) Pd/SBA-15, (b) Pd/SBA-15-T, (c) Pd/SC-10, (d) Pd/SC-10-used, (e) Pd/SC-20, (f) Pd/SC-20-used, (g) Pd/SC-40, (h) Pd/SC-40-used, (i) Pd/SC-80, (j) Pd/SC-80-used, (k) Pd/SC-160 and (l) $\mathrm{Pd} / \mathrm{SC}-160$-used. as shown in Fig. 2(A). The first increase $\left(P / P_{0}<0.1\right)$ is due to the multilayer adsorption on the surface (characteristic of micropores), while the second increase at $P / P_{0}=0.65-0.9$ arises from the capillary condensation in the mesopores with $\mathrm{N}_{2}$ adsorbed on the inner surface [34]. Table 2 summarizes the specific surface area $\left(S_{\mathrm{BET}}\right)$, mean pore diameter $\left(D_{p}\right)$, total pore volume $\left(D_{v}\right)$, miropore surface area $\left(S_{\mathrm{mi}}\right)$ and micropore volume $\left(D_{\mathrm{mi}}\right)$ of all fresh and used catalysts. In general, both the $D_{v}$ and $D_{p}$ of $\mathrm{Pd} / \mathrm{SC}-x$ samples are larger than those of the traditional Pd/SBA-15, increase from $1.06 \mathrm{~cm}^{3} / \mathrm{g}$ and $6.39 \mathrm{~nm}$ to $1.39 \mathrm{~cm}^{3} / \mathrm{g}$ and $8.02 \mathrm{~nm}$, respectively. While the specific surface area of all $\mathrm{Pd} / \mathrm{SC}-\boldsymbol{x}$ samples are more or less lower than that of Pd/SBA-15. Noticeably, the $D_{\mathrm{mi}}$ of all Pd/SC- $x$ samples (aged at $85^{\circ} \mathrm{C}$ ) are much higher than that of the Pd/SBA-15 (aged at $100^{\circ} \mathrm{C}$ ), and the framework $\mathrm{Al}$ probably beneficial for the formation of micropores as the $D_{\mathrm{mi}}$ increases with the decrease in the $\mathrm{Si} / \mathrm{Al}$ molar ratio according to the $t$-plot method (Fig. 2 and Table 2 ). However, the $S_{\mathrm{BET}}, D_{v}$ and $D_{p}$ increase with the raising of the $\mathrm{Si} / \mathrm{Al}$ molar ratio, from $552 \mathrm{~m}^{2} / \mathrm{g}, 0.93 \mathrm{~cm}^{3} / \mathrm{g}$ and $7.49 \mathrm{~nm}$ to $750 \mathrm{~m}^{2} / \mathrm{g}$, $1.39 \mathrm{~cm}^{3} / \mathrm{g}$ and $8.02 \mathrm{~nm}$, respectively (Table 2 ).

\subsubsection{Morphology and framework of mesoporous silica}

Fig. 3 shows the typical SEM images of SBA-15, SC-10 and SC-80 supports. The SC-10 and SC-80 materials are homogeneously dispersed short columns with average pore length of around $450 \mathrm{~nm}$ (Fig. 3C-F), a little longer than that of the platelet materials synthesized by Chen et al. [13]. The short column morphology is very different from the conventional SBA-15, which possesses rod or fiber morphology (Fig. 3A-B). The representative TEM patterns of all synthesized supports are shown in Fig. 4. Well-ordered pores

Table 2

Textural properties of the fresh and used catalysts.

\begin{tabular}{llllcll}
\hline Sample & $\begin{array}{l}S_{\mathrm{BET}^{\mathrm{a}}} \\
\left(\mathrm{m}^{2} / \mathrm{g}\right)\end{array}$ & $\begin{array}{l}D_{\mathrm{v}}{ }^{\mathrm{b}} \\
\left(\mathrm{cm}^{3} / \mathrm{g}\right)\end{array}$ & $\begin{array}{l}D_{\mathrm{p}}{ }^{\mathrm{c}} \\
(\mathrm{nm})\end{array}$ & $\begin{array}{l}S_{\mathrm{mi}}{ }^{\mathrm{d}} \\
\left(\mathrm{m}^{2} / \mathrm{g}\right)\end{array}$ & $\begin{array}{l}D_{\mathrm{mi}^{\mathrm{e}}} \\
\left(\mathrm{cm}^{3} / \mathrm{g}\right)\end{array}$ & $\begin{array}{l}D_{\text {micro }}{ }^{\mathrm{f}} \\
(\%)\end{array}$ \\
\hline Pd/SBA-15 & 759 & 1.06 & 6.3 & 49 & 0.02 & 1.8 \\
Pd/SBA-15-T & 752 & 0.98 & 6.1 & 51 & 0.02 & 2.0 \\
$\mathrm{Pd} / \mathrm{SC}-10$ & 552 & 0.93 & 7.4 & 118 & 0.07 & 7.5 \\
Pd/SC-20 & 580 & 1.1 & 7.5 & 122 & 0.06 & 5.4 \\
Pd/SC-40 & 617 & 1.22 & 7.5 & 98 & 0.05 & 4.1 \\
Pd/SC-80 & 661 & 1.26 & 8.0 & 107 & 0.05 & 3.9 \\
Pd/SC-160 & 750 & 1.39 & 8.0 & 108 & 0.04 & 2.8 \\
Pd/SC-10-used & 531 & 0.91 & 7.4 & 109 & 0.06 & 6.5 \\
Pd/SC-20-used & 569 & 1.06 & 7.5 & 114 & 0.06 & 5.6 \\
Pd/SC-40-used & 605 & 1.2 & 7.4 & 101 & 0.05 & 4.1 \\
Pd/SC-80-used & 653 & 1.23 & 8.0 & 97 & 0.04 & 3.2 \\
Pd/SC-160-used & 744 & 1.37 & 7.9 & 102 & 0.04 & 2.9 \\
\hline
\end{tabular}

a Specific surface area.

b Total pore volume estimated at $P / P_{0}=0.99$.

c $\mathrm{BJH}$ pore diameter calculated from the desorption branch.

d Micropore surface area.

e Micropore volume estimated from the $t$-plot method.

f Percentage of micropore volume to total pore volume $\left(D_{\mathrm{mi}} / D_{\mathrm{v}}\right)$. 


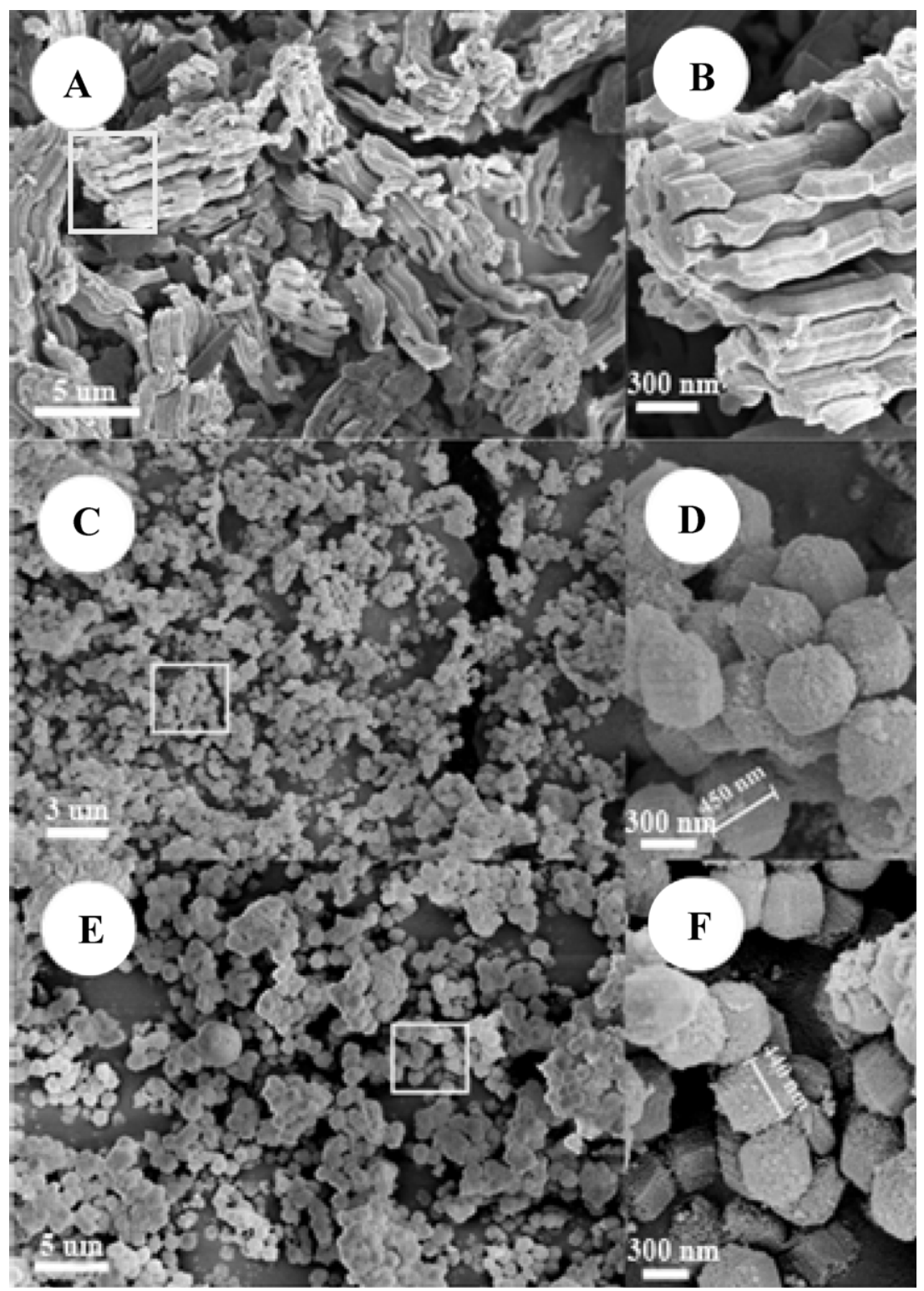

Fig. 3. FE-SEM images of (A-B) SBA-15, (C-D) SC-10 and (E-F) SC-80.

arranged in 2D hexagonal p6mm structure can be observed. Interestingly, the channels of short column SBA-15 run parallel to the short axis, which is obviously different from the SBA-15 type material (channels are preferentially along the long axis) [35]. Besides, all SC- $x$ materials show the similar morphology, indicating that the $\mathrm{Si} / \mathrm{Al}$ ratio has negligible influence on the morphology of final products.

With respect to the elemental composition, the Si/Al ratio is lower than the expected value in all cases (Fig. S1 and Table 1), suggesting that some silicate is still in the solution while Al preferentially incorporates into the solid product. The solid-state ${ }^{27} \mathrm{Al}$ MAS NMR spectroscopy is a widely used technique for identifying the presence of tetra-, penta- and octa-coordinated $\mathrm{Al}$ species in various aluminosilicate materials. Fig. 5 shows the ${ }^{27} \mathrm{Al}$ NMR spectra of SC-10 and SC-20. It can be seen that both spectra have a strong resonance at around $54 \mathrm{ppm}$, while an additional weak resonance (around $0 \mathrm{ppm}$ ) can be observed on the spectra of SC-10. The intense peak at $54 \mathrm{ppm}$ is normally assigned to the chemical shift of tetrahedral coordinated $\mathrm{Al}$, and the peak around $0 \mathrm{ppm}$ is attributed to the octahedral $\mathrm{Al}$ [36]. These results reveal that most of $\mathrm{Al}$ atoms are incorporated into the framework of supports, while a small amount of non-framework $\mathrm{Al}$ is also present under low $\mathrm{Si} / \mathrm{Al}$ ratio (such as $\mathrm{Si} / \mathrm{Al}=10)$.

\subsubsection{Pd dispersion and chemical state of various catalysts}

The $\mathrm{H}_{2}$-TPR and $\mathrm{H}_{2}$ chemisorption experiments were performed to illuminate the reducible properties and Pd dispersion characteristics of the prepared catalysts, as shown in Fig. 6 and Table 1. Only a negative peak between 35 and $55^{\circ} \mathrm{C}$ can be observed for all samples due to the desorption of weakly adsorbed hydrogen and the decomposition of $\mathrm{PdH}_{x}$ [16], suggesting that $\mathrm{Pd}^{2+}$ (i.e., $\mathrm{PdCl}_{2}$ or PdO) gets reduced easily to metallic $\mathrm{Pd}$ in $\mathrm{H}_{2}$ stream. Besides, researchers proposed that the temperature of decomposition peak increases with the decrease in Pd dispersion [37]. In our work, the temperature of desorption peaks increase when raising the Si/Al ratio, indicating the increase of the Pd particle size, i.e., the reduction of Pd dispersion. The SEM-elemental mappings and HAADF-STEM images of Pd/SC-10 and Pd/SC-20 (Fig. S2) reveal that the Pd nanoparticles are homogeneously dispersed (no obvious aggregation) over the supports, and it is interesting to note that the $\mathrm{Pd}$ atoms are located inside the mesoporous channels of the host materials with average particle size of 3.0-4.0 nm. The data of $\mathrm{H} / \mathrm{Pd}$ 


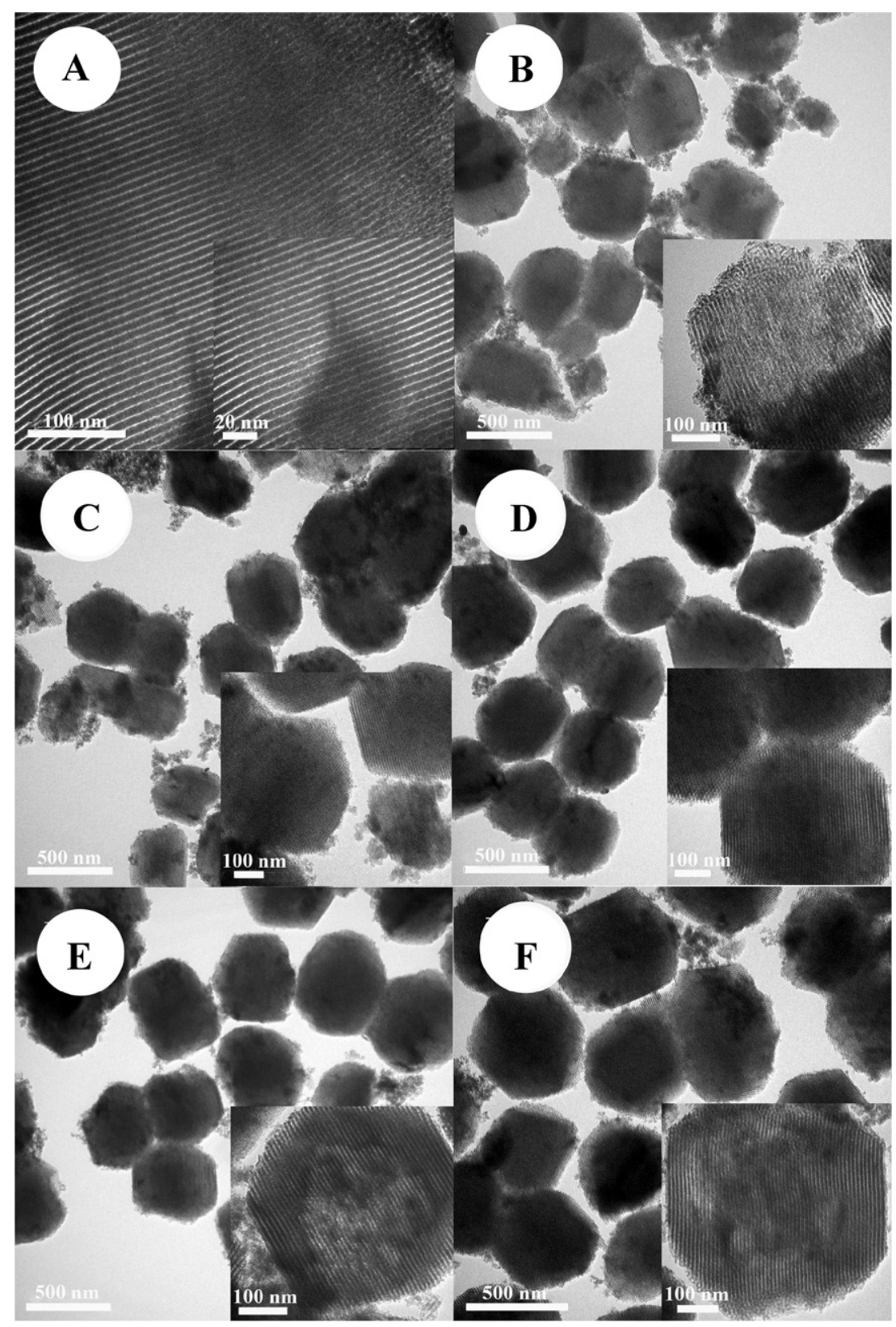

Fig. 4. Representative TEM images of various catalysts: (A) SBA-15, (B) SC-10, (C) SC-20, (D) SC-40, (E) SC-80 and (F) SC-160.

molar ratio and calculated average $\mathrm{Pd}$ nanoparticle size are listed in Table 1. Overall, the H/Pd ratio of Pd/SC- $x$ catalysts (0.34-0.64) appears to be higher than that of the Pd/SBA-15 (0.31), and the $\mathrm{H} / \mathrm{Pd}$ ratio increases with the increase of $\mathrm{Al}$ content. These are well consistent with the XRD and $\mathrm{H}_{2}$-TPR results (Figs. 1(B) and 6). Moreover, the calculated Pd crystallite diameter on Pd/SC-10 and Pd/SC-20 (1.75 and $2.11 \mathrm{~nm}$ ) is smaller than that from the STEM images (3.0-4.0 nm), probably because many Pd particles are too small to be observed, so that only larger visible Pd nanoparticles can be counted in TEM images (Fig. S2 and Table 1).

The surface chemical state of the fresh and used Pd/SC-10 catalyst is shown in Fig. 7. The bind energies of Pd $3 d_{5 / 2}$ and $P d 3 d_{3 / 2}$ for the fresh catalyst are found at around 335.4 and $340.6 \mathrm{eV}$ (i.e., $\mathrm{Pd}^{0}$ ) [38], indicating that the $\mathrm{PdCl}_{2}$ or $\mathrm{PdO}$ are totally reduced in the fresh sample. As for the used Pd/SC-10 catalyst, the Pd 3d peaks shift towards higher binding energy values and the full-width-halfmaximum (FWHM) of Pd 3d peaks shows a substantial increase, which suggests that there are probably more Pd species. Indeed, the used catalyst shows two components at 335.4, 340.6 and 336.7, $341.8 \mathrm{eV}$, which can be attributed to the $\mathrm{Pd}^{0}$ and $\mathrm{Pd}^{2+}$, respectively [39].

\subsubsection{Acidity of synthesized materials}

The $\mathrm{NH}_{3}$-TPD was performed to evaluate the acid strength and acid site amount of prepared Al-containing catalysts, as shown in Fig. 8. Table 3 summarizes the desorption temperature and quantitative mole number of acid sites. All Pd/SC- $x$ catalysts exhibit two desorption peaks in the temperature range of $130-470^{\circ} \mathrm{C}$, indicating that there are two types of acid sties, i.e., low and high temperature peaks correspond to the weak and strong acid sites, respectively [40]. The Pd/SC-10 possesses the largest amount of acid sites with $\mathrm{NH}_{3}$ desorption peaks at 235 and $406^{\circ} \mathrm{C}$. In general, the acid site quantity of $\mathrm{Pd} / \mathrm{SC}-x$ samples increases with the decrease in the $\mathrm{Si} / \mathrm{Al}$ molar ratio (from 0.11 to $0.46 \mathrm{mmol} \mathrm{NH}_{3} / \mathrm{g}_{\text {cat. }}$ ), while there is no certain trend for the number of weak and strong acid sites. 
Table 3

Acidity of the aluminosilicate composite catalysts.

\begin{tabular}{|c|c|c|c|c|c|}
\hline \multirow[t]{2}{*}{ Sample } & \multicolumn{2}{|c|}{ Desorption peak temp. $\left({ }^{\circ} \mathrm{C}\right)$} & \multicolumn{3}{|c|}{ Acidity $\left(\mathrm{mmol} \mathrm{NH}_{3} / \mathrm{g}_{\text {cat. }}\right)$} \\
\hline & $\mathrm{I}$ & II & $\mathrm{I}$ & II & $I+\mathrm{II}$ \\
\hline $\mathrm{Pd} / \mathrm{SC}-10$ & 235 & 406 & 0.09 & 0.35 & 0.44 \\
\hline $\mathrm{Pd} / \mathrm{SC}-20$ & 301 & 464 & 0.31 & 0.06 & 0.37 \\
\hline $\mathrm{Pd} / \mathrm{SC}-40$ & 134 & 395 & 0.10 & 0.13 & 0.23 \\
\hline $\mathrm{Pd} / \mathrm{SC}-80$ & 231 & 378 & 0.11 & 0.02 & 0.13 \\
\hline $\mathrm{Pd} / \mathrm{SC}-160$ & 149 & 342 & 0.07 & 0.04 & 0.11 \\
\hline
\end{tabular}

a Amount of $\mathrm{NH}_{3}$ desorbed at different temperatures.

\subsection{Catalytic performance and stability of prepared catalysts}

The behavior of the synthesized catalysts was evaluated by measuring the toluene conversion versus reaction temperature. Only $\mathrm{CO}_{2}, \mathrm{H}_{2} \mathrm{O}$ and trace $\mathrm{CO}$ were detected during oxidation reactions in all outlet streams, and the carbon mass balance fit in all the cases within $3 \%$. In the temperature range of our experiments no thermal or homogeneous toluene destruction can be observed during the blank test. In general, the Pd/SC- $x$ catalysts possess better toluene oxidation performances (catalytic activity and $\mathrm{CO}_{2}$ selectivity) than the Pd/SBA-15 and Pd/SBA-15$\mathrm{T}$ catalysts, and the most active palladium catalysts (Pd/SC-10) give rise to sharp light-off curves shifted to lower reaction temperatures (toluene total oxidation at $209^{\circ} \mathrm{C}$ ). Table 1 presents the toluene oxidation temperature $\left(T_{10}, T_{50}\right.$ and $\left.T_{90}\right)$ and $\mathrm{CO}_{2}$ selectivity $\left(S_{90}\right)$ over the synthesized catalysts. The temperature decrease in $90 \%$ toluene conversion over Pd/SC $-10\left(T_{90}=198^{\circ} \mathrm{C}\right)$ is about $30^{\circ} \mathrm{C}$ when comparing with Pd/SBA-15 $\left(T_{90}=227^{\circ} \mathrm{C}\right)$ and $\mathrm{Pd} / \mathrm{SBA}-15-\mathrm{T}\left(T_{90}=231^{\circ} \mathrm{C}\right)$. According to the light-off curves in Fig. 9, the toluene catalytic activity order of prepared catalysts is as follows: Pd/SC-10 $\geq \mathrm{Pd} / \mathrm{SC}-20>\mathrm{Pd} / \mathrm{SC}-40 \geq \mathrm{Pd} / \mathrm{SC}-80>\mathrm{Pd} / \mathrm{SC}-$ $160>\mathrm{Pd} / \mathrm{SBA}-15 \geq \mathrm{Pd} / \mathrm{SBA}-15-\mathrm{T}$. Considering the high activity of $\mathrm{Pd} / \mathrm{SC}-10$ catalyst, it is important to compare its activity with other types of noble-metal-supported catalysts used for toluene destruction [24,41-46], as shown in Table 4 . Generally speaking, the $90 \%$

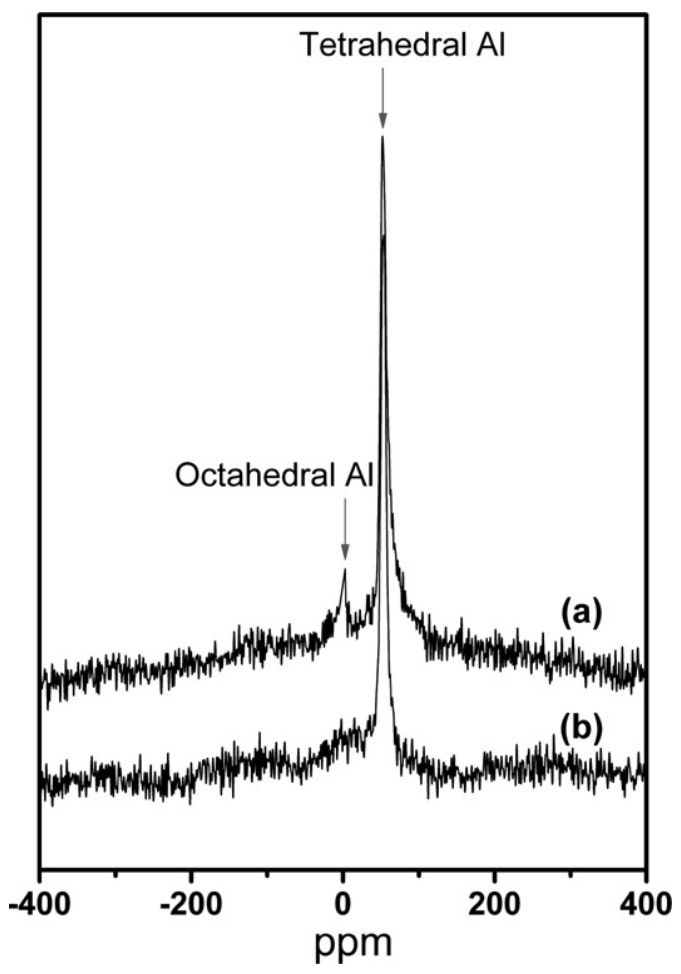

Fig. 5. Solid-state ${ }^{27} \mathrm{Al}$ MAS NMR spectra of (a) SC-10 and (b) SC-20.
Table 4

Summary of some typical noble-metal-loaded catalysts for toluene oxidation.

\begin{tabular}{|c|c|c|c|c|}
\hline \multirow[t]{2}{*}{ Sample } & \multicolumn{2}{|l|}{ Conditions } & \multirow[t]{2}{*}{$T_{90}\left({ }^{\circ} \mathrm{C}\right)$} & \multirow[t]{2}{*}{ Reference } \\
\hline & $C_{\mathrm{Tol}}^{\mathrm{a}}(\mathrm{ppm})$ & $\operatorname{GHSV}\left(\mathrm{h}^{-1}\right)$ & & \\
\hline $0.5 \% \mathrm{Pd} / \mathrm{SC}-10$ & 1000 & 32,000 & 198 & This work \\
\hline $0.5 \% \mathrm{Pd} / \mathrm{MAC}^{\mathrm{b}}$ & 1000 & 19,000 & 370 & {$[2]$} \\
\hline $1.0 \% \mathrm{Pd} / \mathrm{CoAlO}$ & 800 & 30,000 & 230 & [19] \\
\hline $0.5 \mathrm{Pd} / \mathrm{LaFeO}_{3}$ & 1800 & 15,000 & 221 & [34] \\
\hline $1.0 \% \mathrm{Pt} / \mathrm{FS}^{\mathrm{c}}$ & 200 & 33,000 & 200 & [36] \\
\hline $0.5 \% \mathrm{Pd} / \mathrm{mesoZrO}_{2}^{\mathrm{d}}$ & 1000 & 26,000 & 210 & [37] \\
\hline $1.5 \% \mathrm{Pd} / \mathrm{TiO}_{2}$ & 1000 & 30,000 & 235 & [35] \\
\hline $0.3 \% \mathrm{Pd} / \mathrm{ZSM}-5$ & 650 & 26,000 & 270 & [38] \\
\hline $0.5 \% \mathrm{Pd}-1 \% \mathrm{Au} / \mathrm{TiO}_{2}$ & 1000 & 26,000 & 225 & [35] \\
\hline $3.0 \% \mathrm{Au} / \mathrm{CeTiO}$ & 1000 & 26,000 & 290 & [39] \\
\hline
\end{tabular}

a Toluene inlet concentration.

b MAC: Mesoporous activated carbon.

c FS: Fibrous silica.

d Meso $\mathrm{ZrO}_{2}$ : Meso/macroporous zirconia.

toluene oxidation temperatures are higher than $220^{\circ} \mathrm{C}$. Particularly, mesoporous $\mathrm{Pd} / \mathrm{ZrO}_{2}$ also has a good toluene catalytic activity $\left(T_{90}=210^{\circ} \mathrm{C}\right)$, but the catalyst was operated at relatively low GHSV $\left(26,000 \mathrm{~h}^{-1}\right)$. Besides, notable oxidation activity $\left(T_{90}=200^{\circ} \mathrm{C}\right)$ was also found on Pt/FS catalyst, while at higher Pt loading (ca. 1.0 wt.\%)

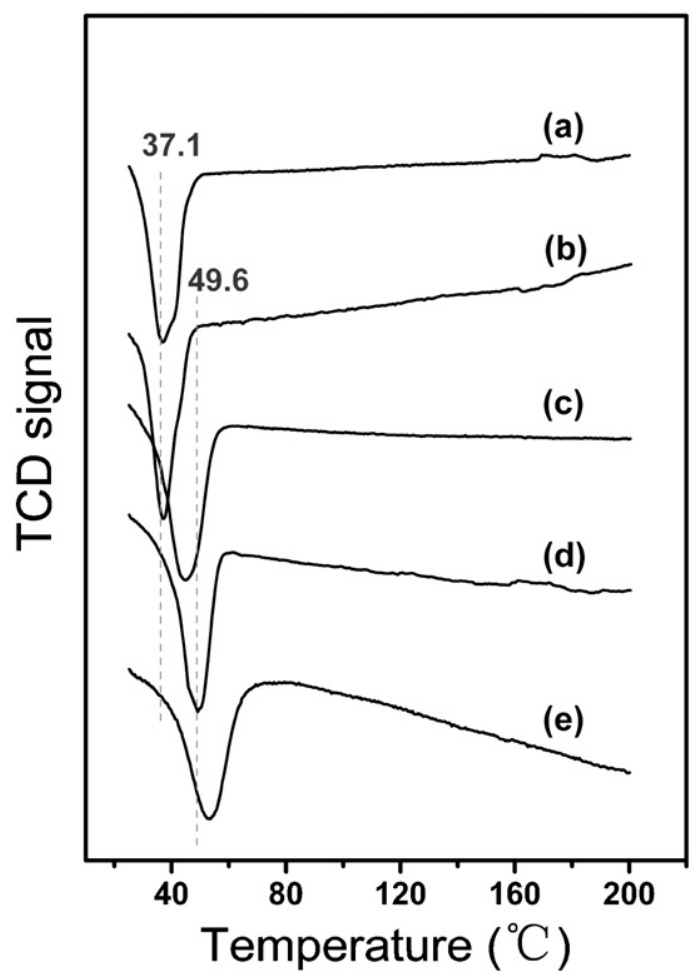

Fig. 6. $\mathrm{H}_{2}-\mathrm{TPR}$ profiles of (a) Pd/SC-10, (b) Pd/SC-20, (c) Pd/SC-40, (d) Pd/SC-80 and (e) Pd/SC-160. 


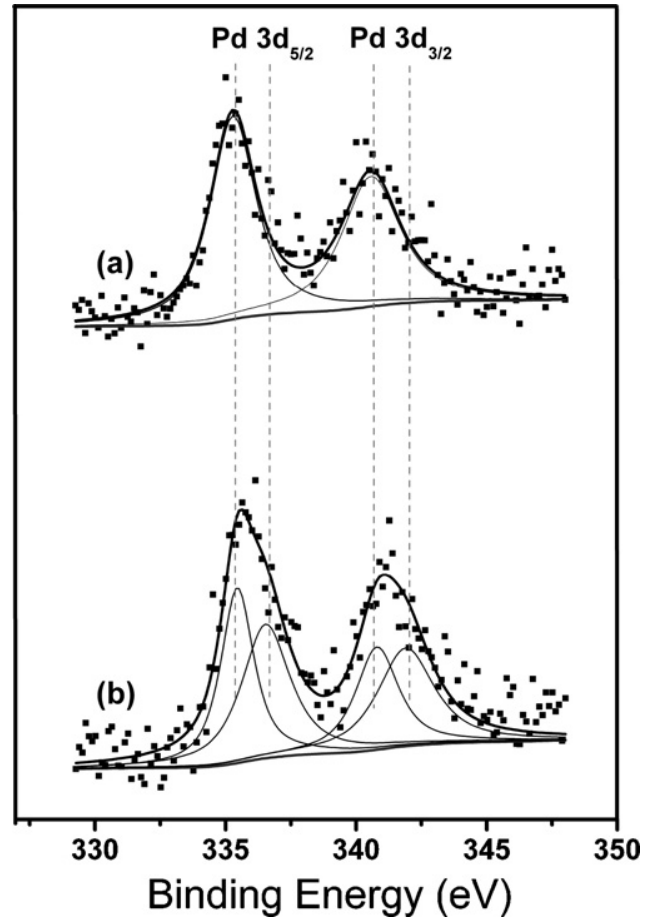

Fig. 7. XPS spectra of (a) Pd/SC-10 and (b) Pd/SC-10-used.

and very low toluene feed concentration (200 ppm). Above results suggest that the $\mathrm{Pd} / \mathrm{SC}-\boldsymbol{x}$ materials in our work are practical and powerful catalysts for toluene oxidation at low temperature. Moreover, the $\mathrm{CO}_{2}$ selectivity over synthesized catalysts at which $90 \%$ conversion of toluene were further investigated, as summarized in Table 1 . The $\mathrm{CO}_{2}$ selectivities of $\mathrm{Pd} / \mathrm{SC}-x$ catalysts are in the range of 98.8-99.5\%, higher than that of Pd/SBA-15 sample (97.8\%).

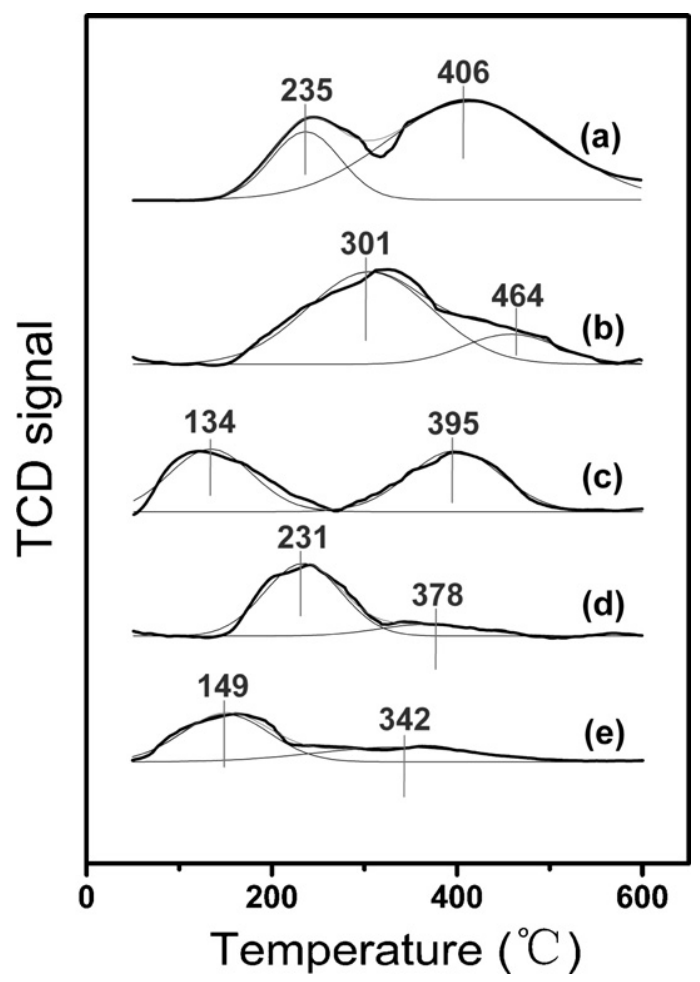

Fig. 8. $\mathrm{NH}_{3}-\mathrm{TPD}$ patterns of various catalysts: (a) $\mathrm{Pd} / \mathrm{SC}-10$, (b) $\mathrm{Pd} / \mathrm{SC}-20$, (c) $\mathrm{Pd} / \mathrm{SC}$ 40, (d) Pd/SC-80 and (e) Pd/SC-160.

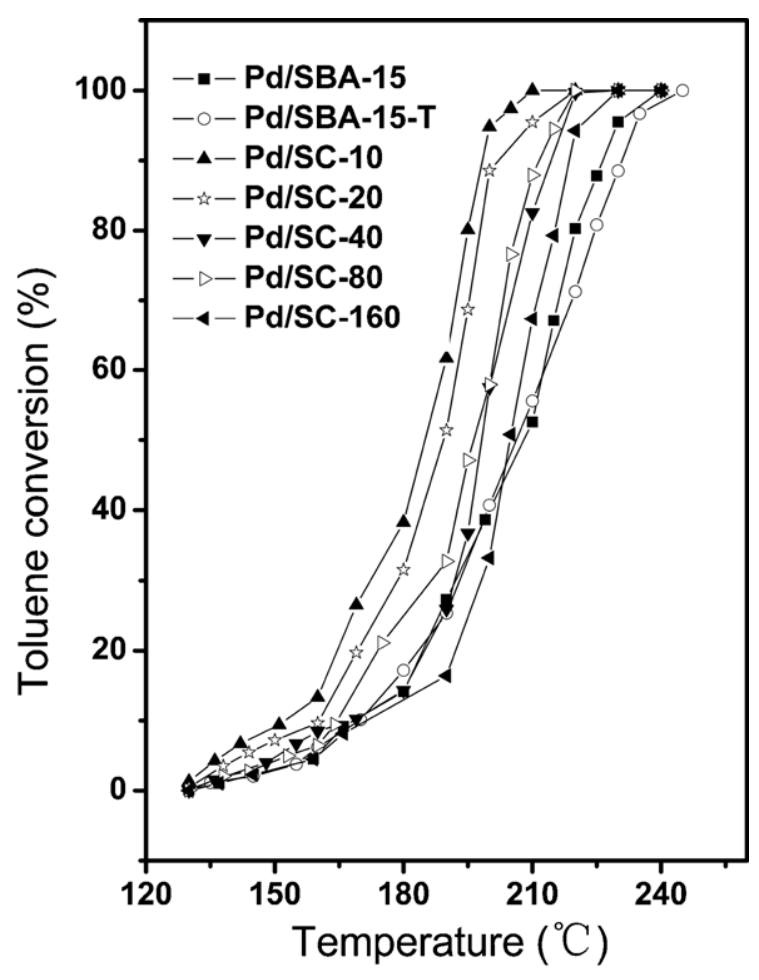

Fig. 9. Light-off curves of toluene oxidation over Pd-loaded catalysts.

Combined with the activity results, it can be inferred that the $\mathrm{CO}_{2}$ selectivity over different catalysts depend on their catalytic activities, i.e., higher catalytic activity leads to a much more thorough toluene oxidation. In order to compare the toluene catalytic activity over various catalysts accurately, the toluene combustion rates $\left(r_{v}\right)$ and turnover frequencies (TOF) were determined from the toluene conversion curves under differential conditions (toluene conversion $<10 \%$ ). The quantity of the exposed Pd determined by $\mathrm{H}_{2}$ chemisorption was used for the TOF calculation (Table 1). It is shown that the TOF data (Table 5) agrees well with the catalytic performance mentioned above, i.e., the Pd-confined catalysts are more active than the Pd/SBA-15, and Pd/SC-10 shows the highest TOF value $\left(1.71 \times 10^{-2} \mathrm{~s}^{-1}\right)$. Based on the calculation results, the Arrhenius plots are plotted and expressed in Fig. 10. According to the Arrhenius plots, the reaction rates and activation energies were estimated, as shown in Table 5 . The apparent activation energy is $77.2 \mathrm{~kJ} / \mathrm{mol}$ for Pd/SC-10, which is much lower than that of Pd/SBA$15(105.4 \mathrm{~kJ} / \mathrm{mol})$ and Pd/SBA-15-T $(92.9 \mathrm{~kJ} / \mathrm{mol})$. The lower value of activation energy correctly suggested the higher catalytic activity of Pd/SC-10 compared to Pd/SBA-15. Correspondingly, the reaction rate of toluene oxidation over Pd/SC-10 $\left(0.30 \mathrm{mmol} / \mathrm{h} \mathrm{g}_{\text {cat. }}\right)$ is much higher than that of Pd/SBA-15 (0.08 mmol/h g cat. $\left._{\text {. }}\right)$ and Pd/SBA-15-T (1.03 $\mathrm{mmol} / \mathrm{h} \mathrm{g}_{\text {cat. }}$ ).

Table 5

Turnover frequencies, activation energies and reaction rates over various catalysts.

\begin{tabular}{llcl}
\hline Sample & TOF $\times 10^{2}\left(\mathrm{~s}^{-1}\right)^{\mathrm{a}}$ & $E_{a}{ }^{\mathrm{b}}(\mathrm{kJ} / \mathrm{mol})$ & $r_{v}{ }^{\mathrm{c}}\left(\mathrm{mmol} / \mathrm{hg}_{\text {cat }}\right)$ \\
\hline Pd/SBA-15 & 0.77 & 105.4 & 0.08 \\
Pd/SBA-15-T & 1.03 & 92.9 & 0.11 \\
Pd/SC-10 & 1.71 & 77.2 & 0.30 \\
Pd/SC-20 & 1.45 & 71.8 & 0.21 \\
Pd/SC-40 & 1.09 & 108.2 & 0.14 \\
Pd/SC-80 & 1.13 & 88 & 0.12 \\
Pd/SC-160 & 1.55 & 100.3 & 0.08 \\
\hline
\end{tabular}

a Turnover frequency obtained at $140^{\circ} \mathrm{C}$

b Apparent activation energy obtained from Arrhenius plot.

c Reaction rate gained at $150^{\circ} \mathrm{C}$. 


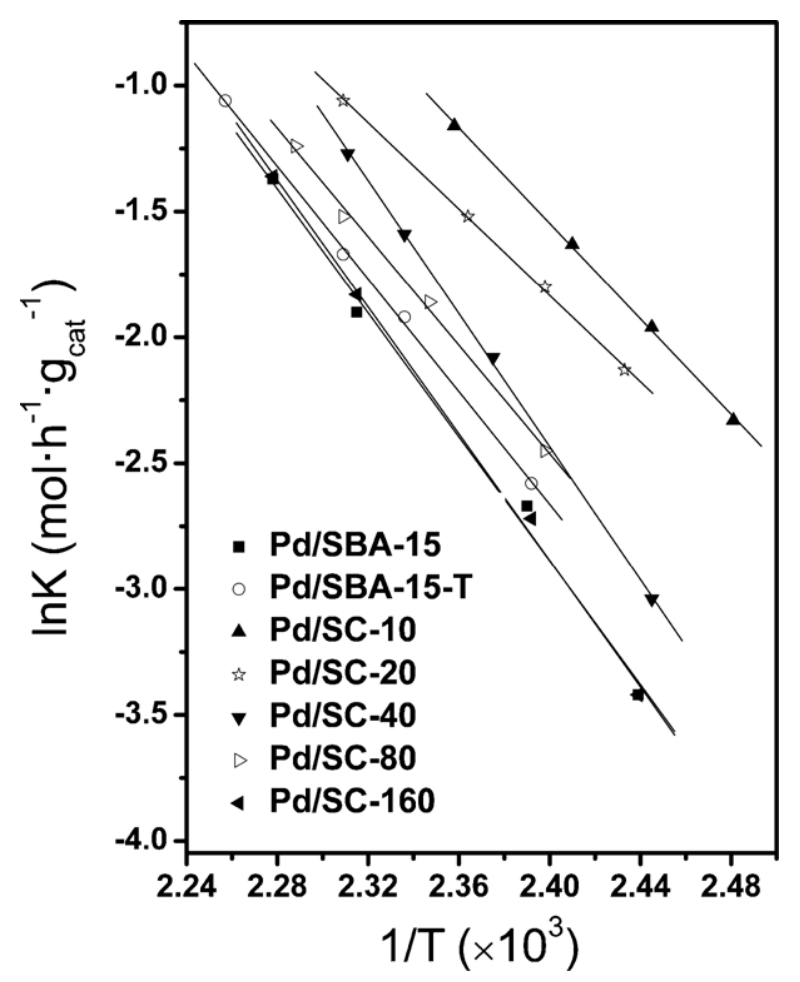

Fig. 10. Arrhenius plot of toluene oxidation reaction (catalyst weight $=300 \mathrm{mg}$; toluene concentration $=1000 \mathrm{ppm} ; \quad G H S V=32,000 \mathrm{~h}^{-1}$; reaction temperature $=130-160^{\circ} \mathrm{C}$.

Fig. 11 shows the stabilities of Pd/SC-10 and Pd/SC-20 at different reaction temperatures. It can be observed that the toluene conversions over Pd/SC-10 and Pd/SC-20 are well maintained without noticeable activity loss at various reaction temperatures. Besides, the textural properties of the used catalysts were characterized by $\mathrm{N}_{2}$ adsorption/desorption, as shown in Fig. 2 and Table 2. The variation of $S_{\mathrm{BET}}, D_{v}$ and $D_{p}$ between the fresh and used catalysts are negligible, which indicates that the structure of the used

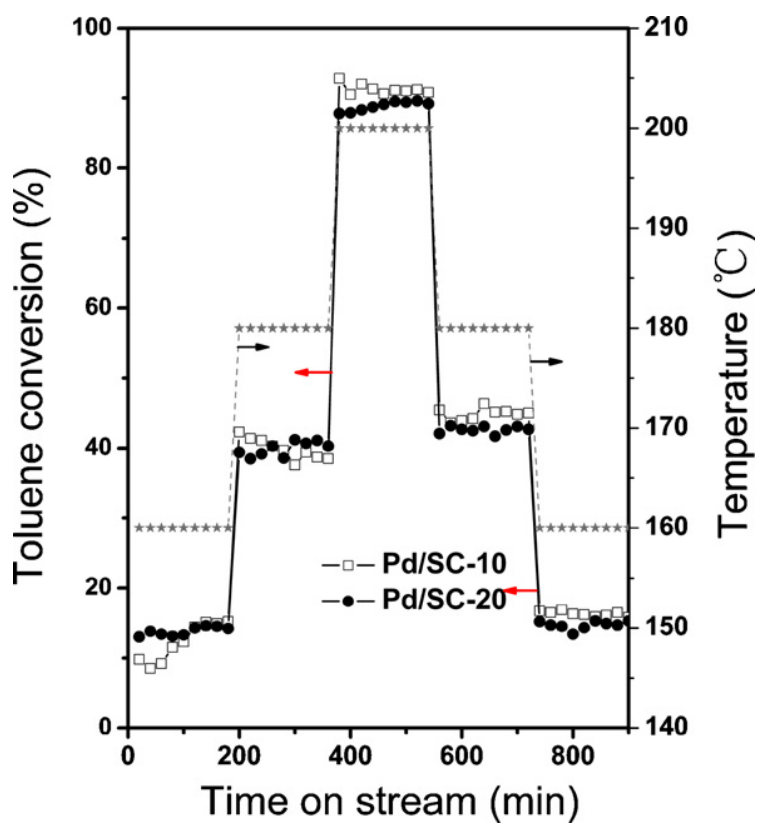

Fig. 11. Stability tests for toluene oxidation with time-on-stream over Pd/SC-10 and $\mathrm{Pd} / \mathrm{SC}-20$.

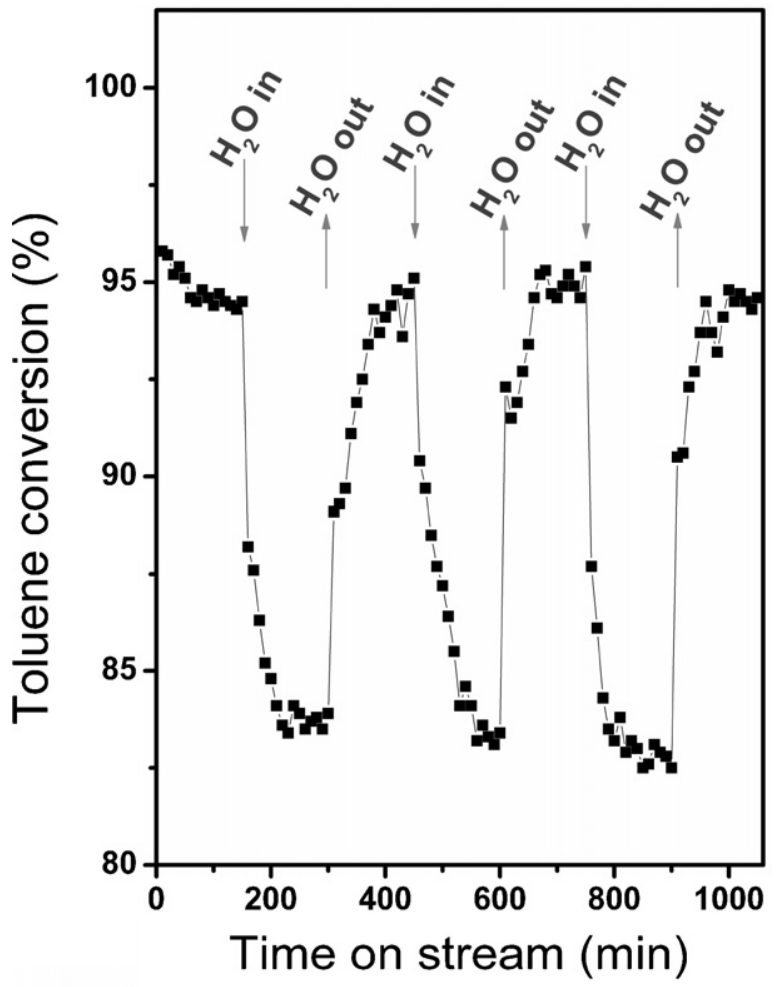

Fig. 12. Toluene oxidation in the presence of water vapor over Pd/SC-10 catalyst (toluene concentration $=1000 \mathrm{ppm}$; $\mathrm{GHSV}=32,000 \mathrm{~h}^{-1}$; reaction temperature $=200^{\circ} \mathrm{C}$; water vapor $=2.0$ vol. $\%$ ).

catalysts are well preserved. As is known, the coke is likely to form over the catalyst with large amount of strong acid sites during VOC oxidation reactions [45], which can lead to catalyst deactivation via poisoning the active sites and blocking the inner pores [47]. In our work, the structure and catalytic performance of the used catalysts can be well maintained, suggesting that no/limited coking occurred. It can be proposed that the mesoporous catalysts with shorter and larger pore channels are favorable for the reactants and products diffusion during oxidation reactions, and hence reduce the possibility of pore blockage and coke. On the other hand, the Pd nanoparticles are well-dispersed in the pore channels of the supports, and the size-restricted mesopores of host silica can effectively prevent the agglomeration of active Pd, which partially resulted in the superior activity and stability of $\mathrm{Pd} / \mathrm{SC}-x$ catalysts.

As is known, most of industrial processes produce flue gases containing water vapor, thus the effect of water vapor on VOC oxidation and catalyst stability in humid conditions always needed careful investigation. Fig. 12 represents the changes in toluene conversion over Pd/SC-10 catalyst at $200^{\circ} \mathrm{C}$ with a stepwise addition and removal of water vapor. It is shown that the catalytic reaction is inhibited by the water molecules as the toluene conversion drops instantaneously by adding of 2.0 vol.\% of water vapor. However, after switching back to the water-free reaction conditions, the toluene conversion increases immediately and return to the initial value gradually, this indicates that the synthesized catalyst has a high tolerance to moisture. It was proposed that the active Pd sites can be blocked by the water molecules involving a quasiequilibrium adsorption-desorption step [48], as shown below:

$2 \mathrm{OH} * \rightarrow \mathrm{H}_{2} \mathrm{O}(g)+\mathrm{O} *+*$

An increase in water concentration in the gas phase would shift the equilibrium towards higher $\mathrm{OH}^{*}$ concentration on the catalyst surface, titrating and reacting with the unsaturated $\mathrm{Pd}$ and $\mathrm{PdO}$ sites to form inactive thermodynamically favored Pd-hydroxides, 
and therefore suppress the combustion process. After switching off the feed of water, the Pd-hydroxides will be decomposed to active palladium sites correspondingly, and thus recover the catalytic activity.

\section{Discussion}

The novel short column SC- $x$ materials with various acidities and expanded microporosity have been successfully synthesized by a simple and reproducible approach, and all Pd-confined catalysts were obtained via an efficient and economical "two-solvents" method. We proved that these materials are powerful catalysts for toluene low temperature elimination, and the catalytic activity of the $\mathrm{Pd} / \mathrm{SC}-x$ can be reasonably explained in terms of the synergetic of the support microporosity and acid property, the Pd dispersion and the $\mathrm{CO}_{2}$ desorption capability.

\subsection{Catalytic performance and textural properties of catalysts}

There are many factors that influence the toluene oxidation efficiency, such as active phase dispersion and valence state, support acidity and material textural properties [9,16,49,50]. Table 2 lists the related textural data of all synthesized catalysts. Any relationship between $S_{\mathrm{BET}}, D_{v}$ and toluene oxidation is not observed. For instance, the Pd/SC-10 owns the lowest $S_{\mathrm{BET}}\left(552.8 \mathrm{~m}^{2} / \mathrm{g}\right)$ and $D_{v}$ $\left(0.93 \mathrm{~cm}^{3} / \mathrm{g}\right)$, while it exhibits the highest toluene oxidation activity. The aforementioned results suggest that the $S_{\mathrm{BET}}$ and $D_{v}$ are not the main factors determining the catalytic performance. Interestingly, the evaluation result indicates that the order of catalytic activity in the present work is positively correlated with that of the micropore volumes. In our previous work [15], we also found that the oxidation performance of Pd-supported catalysts was much dependent on their microporosity as the micropores in the supports can promote the diffusion rate for transport in catalytic processes.

According to the $\mathrm{H}_{2}$ chemisorption analysis, the Pd dispersion order in the synthesized catalysts decreases as follows: Pd $/$ SC $-10>$ Pd/SC-20 $>$ Pd/SC $-40>$ Pd/SC $-80>$ Pd/SC $-160>$ Pd/SBA$15>\mathrm{Pd} / \mathrm{SBA}-15-\mathrm{T}$, as shown in Table 1 . In our work, the order of toluene oxidation activity is fully consistent with the Pd dispersion, indicating that the active phase dispersion is one of the main factors in the determination of the catalytic performance (Fig. 9). According to Pd/SBA-15 $\left(D_{c}=3.6 \mathrm{~nm}, T_{90}=227^{\circ} \mathrm{C}\right)$ and Pd/SBA-15-T $\left(D_{c}=3.8 \mathrm{~nm}, T_{90}=231^{\circ} \mathrm{C}\right)$, it is could be noted that the Pd introduction approach has negligible effect on Pd particle dispersion and toluene oxidation activity. Besides, it is worth noting that the specific surface areas show significantly opposite correlations with the Pd dispersion. For example, the Pd/SC-10 has the lowest $S_{\mathrm{BET}}\left(552.8 \mathrm{~m}^{2} / \mathrm{g}\right)$, while it possesses the best Pd dispersion $\left(D_{c}=1.75 \mathrm{~nm}\right)$. Okumura et al. proposed that the support acid property has significant influence on the dispersion of Pd, and the Brønsted acid sites are responsible for the generation of dispersed Pd species [9,50,51]. As is known, only the tetrahedral Al species contribute to the Brønsted acidity of materials [21]. Herein, most of $\mathrm{Al}$ atoms are tetrahedral coordinated and incorporated into the framework of the supports (Fig. 5). Moreover, the acidity of the synthesized catalysts is in well accordance with the Pd dispersion order, as shown in Tables 2 and 3. Thus, it is reasonable to believe that the support acidity has positive influence on Pd particle dispersion.

Besides, many researchers reported that the performance of Pdsupported catalysts for the oxidation of VOCs is highly dependent on the oxidation state of Pd species $[7,16,24]$. Some investigators proposed that the metallic $\mathrm{Pd}$ (i.e., $\mathrm{Pd}^{0}$ ) is the most active phase in hydrocarbons catalytic oxidation, whereas PdO is inactive [52,53]. While others claimed that the most active phase is the mixture of metallic Pd and PdO, that is, PdO is active in VOC oxidation, while the presence of $\mathrm{Pd}^{0}$ can increase the catalytic activity by providing more active sites for the dissociation of VOC molecules, which allows the overall reaction to proceed more rapidly [54,55]. In our case, the fresh catalyst only contains $\mathrm{Pd}^{0}$ while the used one has mixture of $\mathrm{Pd}^{0}$ and $\mathrm{Pd}^{2+}$ species, suggesting that metallic $\mathrm{Pd}$ is partially oxidized (Fig. 7). Therefore, we could anticipate that both $\mathrm{Pd}^{0}$ and $\mathrm{Pd}^{2+}$ are responsible for the oxidation reactions, and the synergistic effect lead to the high activity for toluene combustion over the mixture of metallic Pd and PdO.

Several models could be used to describe the characteristics of VOC deep catalytic oxidation, such as Power-law model, Langmuir-Hinshelwood model and Mars-van Krevelen model (two-stage redox model). It is generally accepted that the twostage redox model is usually occurred for hydrocarbons oxidation over Pd-supported catalysts [56,57]. That is, a portion of metallic Pd gets oxidized to active $\left[\mathrm{Pd}^{2+} \mathrm{O}^{2-}\right]$ species firstly when $\mathrm{O}_{2}$ is present (in accordance with the XPS results), and subsequently the oxidized catalyst is reduced by hydrocarbon and at the same time the hydrocarbon is oxidized to $\mathrm{CO}_{2}$ and $\mathrm{H}_{2} \mathrm{O}$ (step a). Afterwards, the catalyst redox center $\left(\mathrm{Pd}^{0}\right)$ is oxidized by the stream $\mathrm{O}_{2}$ to recover $\left[\mathrm{Pd}^{2+} \mathrm{O}^{2-}\right]$ through adsorption and dissociation of $\mathrm{O}_{2}$ (step $\mathrm{b}$ ). Many researchers testified that the oxidation state of Pd particles is significantly dependent on the acidic and basic properties of support [50,51]. Namely, Pd particles loaded on acidic supports were more easily oxidized than supported on the neutral or basic support as the acidic supports with electrophilic character resulted in the electron deficient on Pd atoms, thus the Pd surface was easily oxidized, which was directly testified by Okumura et al. via EXAFS study [50]. According to the Mars-van Krevelen model, the facile oxidation of metallic Pd (i.e., $\mathrm{Pd}^{0} \rightarrow \mathrm{Pd}^{2+}$ ) can promote the step (b) to the right side, and hence accelerate the oxidation reaction.

\subsection{Adsorption/desorption properties of $\mathrm{CO}_{2}$ and toluene over different catalysts}

Currently, considerable research effort has been mostly concentrated on the understanding of the role of active Pd phase on the hydrocarbon catalytic activity. However, little attention has been given to the exploration of the influence of the support textural characteristic on hydrocarbon adsorption and reaction product desorption properties, and at the same time the relationship between the adsorption/desorption of reactant/product and VOCs catalytic activity is seldom considered $[49,58,59]$.

In this work, the toluene adsorption/desorption performances over the fresh catalysts were investigated through toluene-TPD technique, as shown in Fig. 13. Among all materials, the Pd/SC-10 has the lowest toluene adsorption capability with the main desorption peak at $128^{\circ} \mathrm{C}$. In sharp contrast, the Pd/SC-160 possesses the best toluene adsorption performance. The toluene adsorption capability of all synthesized catalysts decreases as follows: Pd/SC$160>\mathrm{Pd} / \mathrm{SC}-80 \gg \mathrm{Pd} / \mathrm{SC}-40>\mathrm{Pd} / \mathrm{SC}-20>\mathrm{Pd} / \mathrm{SC}-10$ (Fig. 13). Besides, it should be noted that the toluene desorption amount increases with the raising of the $\mathrm{Si} / \mathrm{Al}$ molar ratios. Obviously, the toluene adsorption performances are inconsistent with the toluene oxidation activity, which indicates that the toluene adsorption capability is not the main factor determining the catalytic performance.

Fig. 14 displays the $\mathrm{CO}_{2}$ desorption patterns of various catalysts. It can be observed that all synthesized catalysts possess different $\mathrm{CO}_{2}$ desorption capabilities. Pd/SC-10 possesses the best $\mathrm{CO}_{2}$ desorption performance as the primary desorption peak is located at the lowest temperature $\left(61^{\circ} \mathrm{C}\right)$. In addition, $\mathrm{Pd} / \mathrm{SC}-20$ also has a good $\mathrm{CO}_{2}$ desorption ability with the main desorption peaks centered at $73{ }^{\circ} \mathrm{C}$. While the traditional Pd/SBA-15 catalyst is unfavorable for $\mathrm{CO}_{2}$ desorption. Clearly, the $\mathrm{CO}_{2}$ desorption performance probably has profound positive effects on hydrocarbon 


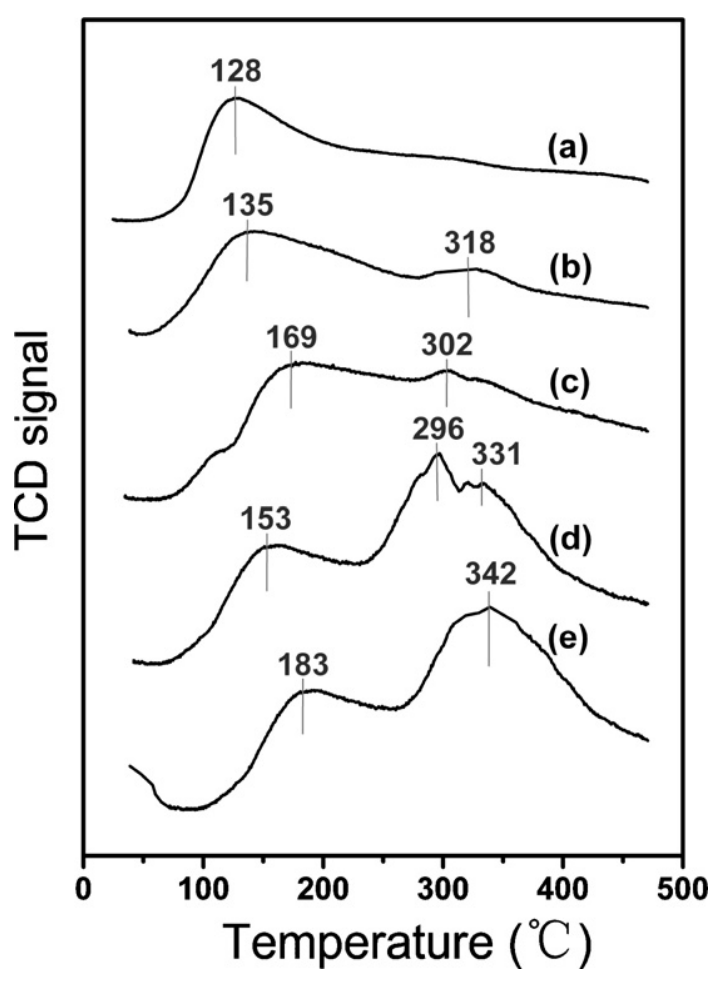

Fig. 13. Toluene-TPD patterns of (a) Pd/SC-10, (b) Pd/SC-20, (c) Pd/SC-40, (d) Pd/SC80 and (e) Pd/SC-160.

catalytic activity in terms of the two-stage redox process as step (a) can be directly promoted by accelerating the $\mathrm{CO}_{2}$ desorption from the catalyst surface and simultaneously more reduced catalytic centers are released and step (b) is also speeded up. Indeed,

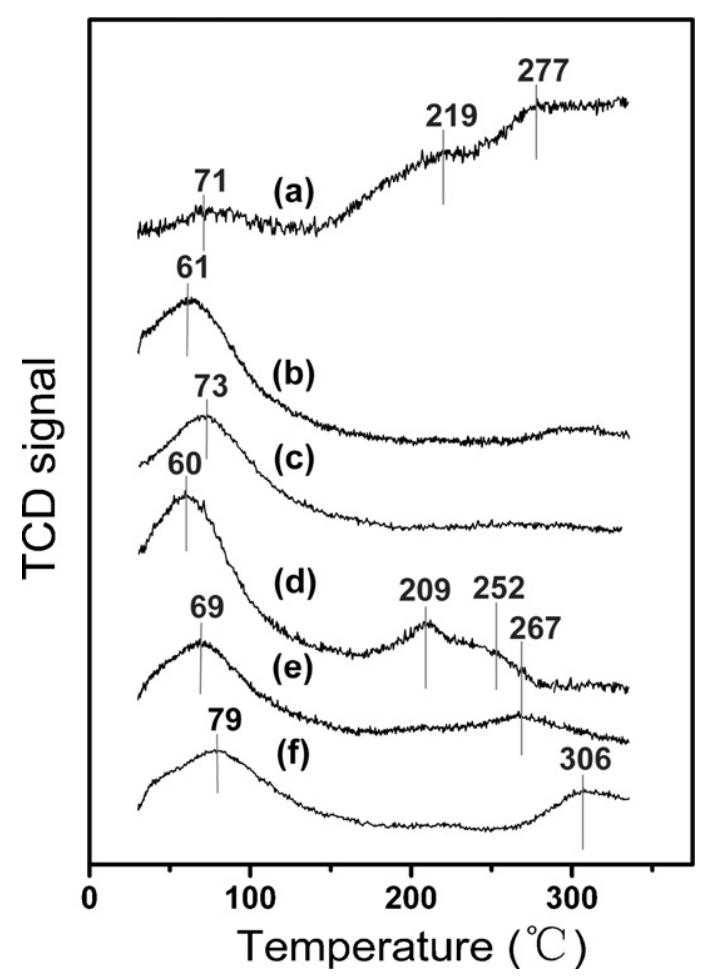

Fig. 14. $\mathrm{CO}_{2}$-TPD patterns of synthesized catalysts: (a) Pd/SBA-15, (b) Pd/SC-10, (c) Pd/SC-20, (d) Pd/SC-40, (e) Pd/SC-80 and (f) Pd/SC-160. the order of $\mathrm{CO}_{2}$ desorption capability is in accordance with the toluene catalytic activity (Figs. 9 and 14).

\section{Conclusions}

The short column mesoporous siliceous supports with expanded microporosity and controllable acidities have been successfully synthesized. In addition, the Pd/SC- $x$ catalysts with nanometric Pd located in their pore channels were prepared through an economical and reproducible "two-solvents" method. The Al atoms prefer tetrahedral coordinated in the framework of the support and the acid sites in the catalysts are favorable for the Pd nanoparticles dispersion and metallic Pd oxidation. Moreover, both the microporosity and $\mathrm{CO}_{2}$ desorption capability possess significant influences on toluene catalytic efficiency. The water vapor has negative effects on the toluene oxidation process, ascribable to the formation of inactive Pd-hydroxides. All Pd-confined materials act as powerful catalysts for toluene low temperature oxidation, and the catalytic performance can be explained in the light of the synergetic of the support microporosity, the active phase dispersion, the acidity and the $\mathrm{CO}_{2}$ desorption capability. We can rationally expect that these novel materials are effective and promising catalysts in the elimination of VOCs, and simultaneously have other potential applications in catalysis, separation and adsorption processes.

\section{Acknowledgements}

This work is financially supported by the National Science and Technology Ministry Program of China (2008BAC32B03), the Science and Technology Project of Xiamen (3502Z20102015) and National Natural Science Foundation (20725723, 21107106), and the Natural Science Foundation of Fujian Province (2060203).

\section{Appendix A. Supplementary data}

Supplementary data associated with this article can be found, in the online version, at doi:10.1016/j.apcatb.2011.09.017.

\section{References}

[1] B. de Rivas, R. López-Fonseca, M.A. Gutiérrez-Ortiz, J.I. Gutiérrez-Ortiz, Appl. Catal. B: Environ. 101 (2011) 317-325.

[2] M. Magureanu, D. Piroi, N.B. Mandache, V.I. Pârvulescu, V. Pârvulescu, B. Cojocaru, C. Cadigan, R. Richards, H. Daly, C. Hardacre, Appl. Catal. B: Environ. 104 (2011) 84-90.

[3] J. Okal, M. Zawadzki, Appl. Catal. B: Environ. 105 (2011) 182-190.

[4] M.J. Kirkpatrick, E. Odic, J.-P. Leininger, G. Blanchard, S. Rousseau, X. Glipa, Appl. Catal. B: Environ. 106 (2011) 160-166.

[5] M. Ousmane, L.F. Liotta, G. Di Carlo, G. Pantaleo, A.M. Venezia, G. Deganello, L. Retailleau, A. Boreave, A. Giroir-Fendler, Appl. Catal. B: Environ. 101 (2011) 629-637.

[6] M. Saleh, Saqer, I. Dimitris, Kondarides, E. Xenophon, Verykios, Appl. Catal. B: Environ. 103 (2011) 275-286.

[7] C. He, P. Li, J. Cheng, H.L. Wang, J.J. Li, Q. Li, Z.P. Hao, Appl. Catal. A Gen. 382 (2010) 167-175.

[8] T. Garcia, B. Solsona, D.M. Murphy, K.L. Antcliff, S.H. Taylor, J. Catal. 229 (2005) $1-11$.

[9] K. Okumura, T. Kobayashi, H. Tanaka, M. Niwa, Appl. Catal. B: Environ. 44 (2003) 325-331.

[10] P.F. Fulvio, S. Pikus, M. Jaroniec, ACS Appl. Mater. Interfaces 2 (2010) 134-142.

[11] H. Zhang, J.M. Sun, D. Ma, G. Weinberg, D.S. Su, X.H. Bao, J. Phys. Chem. B 110 (2006) 25908-25915.

[12] D.Y. Zhao, J.Y. Sun, Q.Z. Li, G.D. Stucky, Chem. Mater. 12 (2000) 275-279.

[13] S.Y. Chen, C.Y. Tang, W.T. Chuang, J.J. Lee, Y.L. Tsai, J.C.C. Chan, C.Y. Lin, Y.C. Liu, S. Cheng, Chem. Mater. 20 (2008) 3906-3916.

[14] F. Wang, J.S. Li, J.F. Yuan, X.Y. Sun, J.Y. Shen, W.Q. Han, L.J. Wang, Catal. Commun. 12 (2011) 1415-1419. 
[15] C. He, Q. Li, P. Li, Y.F. Wang, X.Y. Zhang, J. Cheng, Z.P. Hao, Chem. Eng. J. 162 (2010) 901-909.

[16] C. He, J.J. Li, P. Li, J. Cheng, Z.P. Hao, Z.P. Xu, Appl. Catal. B: Environ. 96 (2010) 466-475.

[17] M. Kruk, M. Jaroniec, C.H. Ko, R. Ryoo, Chem. Mater. 12 (2000) 1961-1968.

[18] V. Sazo, C.M. López, G. Gonzalez, A. Arregui, M.E. Gomes, C. Urbina, Appl. Catal. A Gen. 380 (2010) 118-124.

[19] S. Sumiya, Y. Oumi, T. Uozumi, T. Sano, J. Mater. Chem. 11 (2001) 1111-1115.

[20] Z. Luan, M. Hartmann, D. Zhao, W. Zhou, L. Kevan, Chem. Mater. 11 (1999) 1621-1627.

[21] S. Wu, Y. Han, Y.C. Zou, J.W. Song, L. Zhao, Y. Di, S.Z. Liu, F.S. Xiao, Chem. Mater 16 (2004) 486-492.

[22] Z.J. Wang, Y.B. Xie, C.J. Liu, J. Phys. Chem. C 112 (2008) 19818-19824.

[23] Y. Zhang, F.L.-Y. Lam, X. Hu, Z. Yan, P. Sheng, J. Phys. Chem. C 111 (2007) $12536-12541$.

[24] P. Li, C. He, J. Cheng, C.Y. Ma, B.J. Dou, Z.P. Hao, Appl. Catal. B: Environ. 101 (2011) 570-579.

[25] J. Bedia, J.M. Rosas, J. Rodríguez-Mirasol, T. Cordero, Appl. Catal. B: Environ. 94 (2010) 8-18.

[26] H.L. Tidahy, S. Siffert, J.-F. Lamonier, R. Cousin, E.A. Zhilinshaya, A. Aboukaïs, B.-L. Su, X. Canet, G. De Weireld, M. Frère, J.-M. Giraudon, G. Leclercq, Appl. Catal. B: Environ. 70 (2007) 377-383.

[27] C. He, P. Li, H.L. Wang, J. Cheng, X.Y. Zhang, Y.F. Wang, Z.P. Hao, J. Hazard. Mater. 181 (2010) 996-1003.

[28] D.H. Lin, Y.X. Jiang, Y. Wang, S.G. Sun, J. Nanomater. 2008 (2008) 1-10.

[29] G. Laugel, J. Arichi, H. Guerba, M. Molière, A. Kiennemann, F. Garin, B. Louis, Catal. Lett. 125 (2008) 14-21.

[30] D.Y. Zhao, J.L. Feng, Q.S. Huo, N. Melosh, G.H. Fredrickson, B.F. Chmelka, G.D. Stucky, Science 279 (1998) 548-552.

[31] N. Mahata, V. Vishwanathan, J. Catal. 196 (2000) 262-270.

[32] T. Tsoncheva, L. Ivanova, J. Rosenholm, M. Linden, Appl. Catal. B: Environ. 89 (2009) 365-374.

[33] K.S.W. Sing, D.H. Everett, R.A.W. Haul, L. Moscou, R.A. Pierotti, J. Rouquérol, T. Siemieniewska, Pure Appl. Chem. 57 (1985) 603-619.

[34] K. Miyazawa, S. Inagaki, Chem. Commun. 212 (2000) 1-2122.

[35] H. Zhang, J.M. Sun, D. Ma, X.H. Bao, A. Klein-Hoffmann, G. Weinberg, D.S. Su, R Schlögl, J. Am. Chem. Soc. 126 (2004) 7440-7441.

[36] G.M. Kumaran, S. Garg, K. Soni, M. Kumar, J.K. Gupta, L.D. Sharma, K.S.R. Rao, G.M. Dhar, Microporous Mesoporous Mater. 114 (2008) 103-109.

[37] P. Sangeetha, K. Shanthi, K.S. Rama Rao, B. Viswanathan, P. Selvam, Appl. Catal. A: Gen. 353 (2009) 160-165.
[38] A.H. Padmasri, A. Venugopal, J. Krishnamurthy, K.S. Rama Rao, P. Kanta Rao, J. Phys. Chem. B 106 (2002) 1024-1031.

[39] J.Y. Luo, M. Meng, X. Li, X.G. Li, Y.Q. Zha, T.D. Hu, Y.N. Xie, J. Zhang, J. Catal. 254 (2008) 310-324.

[40] K. Faungnawakij, R. Kikuchi, T. Matsui, T. Fukunaga, K. Eguchi, Appl. Catal. A: Gen. 333 (2007) 114-121.

[41] J.M. Giraudon, A. Elhachimi, F. Wyrwalski, S. Siffert, A. Aboukais, J.-F. Lamonier, G. Leclercq, Appl. Catal. B: Environ. 75 (2007) 157-166.

[42] M. Hosseini, S. Siffert, H.L. Tidahy, R. Cousin, J.-F. Lamonier, A. Aboukais, A. Vantomme, M. Roussel, B.-L. Su, Catal. Today 122 (2007) 391-396.

[43] J. Uchisawa, K. Kosuge, T. Nanba, S. Masukawa, A. Obuchi, Catal. Lett. 133 (2009) 314-320.

[44] H.L. Tidahy, M. Hosseni, S. Siffert, R. Cousin, J.-F. Lamonier, A. Aboukaïs, B.-L. Su, J.-M. Giraudon, G. Leclerq, Catal. Today 137 (2008) 335-339.

[45] C. He, J.J. Li, J. Cheng, L.D. Li, P. Li, Z.P. Hao, Z.P. Xu, Ind. Eng. Chem. Res. 48 (2009) 6930-6936.

[46] C. Gennequin, M. Lamallem, R. Cousin, S. Siffert, V. Idakiev, T. Tabakova, A. Aboukaïs, B.L. Su, J. Mater. Sci. 44 (2009) 6654-6662.

[47] E. Díaz, S. Ordóñez, A. Vega, J. Coca, Appl. Catal. B: Environ. 56 (2005) 313-322.

[48] K. Fujimoto, F.H. Ribeiro, M. Avalos-Borja, E. Iglesia, J. Catal. 179(1998) 431-442.

[49] W.G. Shim, J.W. Lee, S.C. Kim, Appl. Catal. B: Environ. 84 (2008) 133-141.

[50] K. Okumura, S. Matsumoto, N. Nishiaki, M. Niwa, Appl. Catal. B: Environ. 40 (2003) 151-159.

[51] K. Okumura, J. Amano, N. Yasunobu, M. Niwa, J. Phys. Chem. B 104 (2000) 1050-1057.

[52] T. Garcia, B. Solsona, D. Cazorla-Amoros, A. Linares-Solano, S.H. Taylor, Appl. Catal. B: Environ. 62 (2006) 66-76.

[53] S.C. Kim, S.W. Nahm, W.G. Shim, J.W. Lee, H. Moon, J. Hazard. Mater. 141 (2007) 305-314.

[54] W.S. Epling, G.B. Hoflund, J. Catal. 182 (1999) 5-12.

[55] J.J. Li, Z. Jiang, Z.P. Hao, X.Y. Xu, Y.H. Zhuang, J. Mol. Catal. A: Chem. 225 (2005) $173-179$

[56] S.K. Gangwal, M.E. Mullis, J.J. Spivey, P.R. Caffrey, Appl. Catal. 36 (1988) 231-247.

[57] A. Aranzabal, J.A. González-Marcos, J.L. Ayastuy, J.R. González-Velasco, Chem. Eng. Sci. 61 (2006) 3564-3576.

[58] E. Diaz, B. de Rivas, R.L. Fonseca, S. Ordonez, J.I.G. Ortiz, J. Chromatogr. A 1116 (2006) 230-239.

[59] H.L. Tidahy, S. Siffert, J.F. Lamonier, R. Cousin, E.A. Zhilinskaya, A. Aboukais, B.L. Su, X. Canet, G.D. Weireld, M. Frere, J.M. Giraudon, G. Leclercq, Appl. Catal. A: Gen. 310 (2006) 61-69. 